\title{
Toxic effects of extracellular histones and their neutralization by vitreous in retinal detachment
}

\author{
Hiroki Kawano ${ }^{1}$, Takashi Ito ${ }^{2}$, Shingo Yamada ${ }^{3}$, Teruto Hashiguchi ${ }^{4}$, Ikuro Maruyama ${ }^{2}$, Toshio Hisatomi ${ }^{5}$, \\ Makoto Nakamura ${ }^{6}$ and Taiji Sakamoto ${ }^{1}$
}

Histones are DNA-binding proteins and are involved in chromatin remodeling and regulation of gene expression. Histones can be released after tissue injuries, and the extracellular histones cause cellular damage and organ dysfunction. Regardless of their clinical significance, the role and relevance of histones in ocular diseases are unknown. We studied the role of histones in eyes with retinal detachment (RD). Vitreous samples were collected during vitrectomy, and the concentration of histone H3 was measured by enzyme-linked immunosorbent assay. The location of the histones and related molecules was examined in a rat RD model. The release of histones and their effects on rat retinal progenitor cells R28 and ARPE-19 were evaluated in vitro. In addition, the protective role of the vitreous body against histones was tested. The intravitreal concentration of histones was higher in eyes with RD (mean, $30.9 \pm 9.8 \mathrm{ng} / \mathrm{ml}$ ) than in control eyes (below the limit of detection, $P<0.05$ ). In the rat RD model, histone $\mathrm{H} 3$ was observed on the outer side of the detached retina and was associated with photoreceptor death. Histone $\mathrm{H} 3$ was released from cultured R28 by oxidative stress. Histones at a concentration $10 \mu \mathrm{g} / \mathrm{ml}$ induced the production of interleukin-8 in ARPE-19 cells (2.5-fold increase, $P<0.05)$ that was mediated through the ERK1/2- and p38 MAPK-dependent pathways and Toll-like receptor 4. Histones were toxic to cells at concentrations of $\geq 20 \mu \mathrm{g} / \mathrm{ml}$. Vitreous body or hyaluronan decreased toxicity of histones by inhibiting diffusion of histones. These results indicate that histones are released from retinas with RD and may modulate the subretinal microenvironment by functioning as damage-associated molecular pattern molecules, thereby inducing proinflammatory cytokines or cell toxicity. In addition, the important role of the vitreous body and hyaluronan in protecting the retina from these toxic effects is suggested.

Laboratory Investigation (2014) 94, 569-585; doi:10.1038/labinvest.2014.46; published online 10 March 2014

KEYWORDS: cytokine; cytotoxicity; DAMPs; extracellular histones; retinal detachment

Histones are highly alkaline proteins found in the nuclei of eukaryotic cells, and they are involved in the packaging and arranging of DNA into functional units. Histones are also released from neutrophils as neutrophil extracellular traps (NETs), and these NETs play important roles in protecting cells against exogenous microbes. ${ }^{1,2}$ Recent studies have also examined the perturbing side of histones. ${ }^{3}$ Thus, $\mathrm{Xu}$ et $a l^{4}$ reported that extracellular histones, which are released from dying cells, contribute to the dysfunction of endothelial cells, organ failure, and death during sepsis. In addition, endogenous histones have been reported to enhance sterile inflammation by increasing cytokine production through
Toll-like receptors (TLRs). ${ }^{5,6}$ Therefore, histones are considered to be an important component of damageassociated molecular pattern (DAMP) molecules $^{7}$ and are being extensively investigated to determine their role in different pathological conditions.

Rhegmatogenous retinal detachment (RRD) is a physical separation of the neural layer of the retina from the retinal pigment epithelium (RPE) and is caused by a retinal break or tear. The separation results in progressive photoreceptor death. ${ }^{8,9}$ Because the death is progressive and irreversible, a long duration of RD can lead to severe and permanent vision reduction. Thus, new insights on the pathophysiology of $\mathrm{RD}$

\footnotetext{
${ }^{1}$ Department of Ophthalmology, Kagoshima University Graduate School of Medical and Dental Sciences, Kagoshima, Japan; ${ }^{2}$ Department of Systems Biology in Thromboregulation, Kagoshima University Graduate School of Medical and Dental Sciences, Kagoshima, Japan; ${ }^{3}$ Shino-Test Corporation, Kanagawa, Japan; ${ }^{4}$ Department of Laboratory and Vascular Medicine, Kagoshima University Graduate School of Medical and Dental Sciences, Kagoshima, Japan; ${ }^{5}$ Department of Ophthalmology, Kyushu University, Fukuoka, Japan and ${ }^{6}$ Department of Ophthalmology, Kobe University, Kobe, Japan

Correspondence: Professor T Sakamoto, MD, PhD, Department of Ophthalmology, Kagoshima University Graduate School of Medical and Dental Sciences, 8-35-1, Sakuragaoka, Kagoshima 890-8520, Japan.

E-mail: tsakamot@m3.kufm.kagoshima-u.ac.jp

Received 3 September 2013; revised 8 January 2014; accepted 5 February 2014
} 
are important. In addition, the retina is an easily accessible part of the brain, and thus it offers a unique opportunity to study the central nervous system. We have reported that the high-mobility group box 1 (HMGB1) protein was elevated in the vitreous of human eyes with RD. This protein played a significant role in the pathological and healing processes as DAMP molecules. ${ }^{10,11}$

The vitreous has different properties that helps maintain its transparency and its ability to protect the retina. However, its exact role and mechanisms of action have not been determined. ${ }^{12,13}$

Thus, the purpose of this study was to determine whether extracellular histones are released from dying retinas with $\mathrm{RD}$, and whether they affect the subretinal microenvironment as do the DAMP molecules. We shall show that the concentration of histone $\mathrm{H} 3$, which is component of the core histones, in the vitreous of eyes with RD was higher than that in control eyes. The histones caused cytokine release and cell toxicity on the retina and RPE cells in vitro. Interestingly, the damaging effects of these histones were alleviated by the vitreous body. Furthermore, these effects were due to hyaluronan in the vitreous. These findings suggest that there may be defensive mechanisms against extracellular histones from the damaged retinas in eyes after tissue injury.

\section{MATERIALS AND METHODS Reagents}

Calf thymus histones (H9250) were purchased from SigmaAldrich (St Louis, MO, USA). Antibodies against histone H3 (ab1791) and control rabbit polyclonal IgG (ab27478) were purchased from Abcam (Cambridge, UK). The mouse antiCD68 monoclonal antibody (MCA341R) and control mouse IgG (MCA1209) were purchased from Serotec (Raleigh, NC, USA). The mitogen-activated protein kinase (MEK) inhibitor, U0126, was purchased from Promega (Madison, WI, USA). The p38 mitogen-activated protein kinase (MAPK) inhibitor, SB203580, was purchased from Calbiochem (La Jolla, CA, USA), and the JNK inhibitor, SP600125, was purchased from Wako (Osaka, Japan). Purified, functional grade anti-human CD284 (TLR4), anti-human CD282 (TLR2), and mouse IgG2a K isotype control were obtained from eBioscience (San Diego, CA, USA).

\section{Human Vitreous Samples}

The procedures used in this study were approved by the Ethics Committee of Kagoshima University Hospital and were performed in accordance with the Declaration of Helsinki. All surgeries were performed at Kagoshima University Hospital, and all patients provided written informed consent before treatment. Undiluted vitreous samples $(0.5-0.7 \mathrm{ml})$ were collected from approximately the same site during vitrectomy as described. ${ }^{10,11}$ The vitreous was injected into sterile tubes, immediately placed on ice, centrifuged to remove cells and debris, and stored at $-80^{\circ} \mathrm{C}$ until analyses. The clinical histories of all patients were obtained from their medical records. In patients with $\mathrm{RD}$, the preoperative data included the time from onset of symptoms to surgery and the extent of the detached retina. These parameters were determined as previously described. ${ }^{11}$

Measurements of the vitreous levels of histone $\mathrm{H} 3$ and the levels of six inflammatory molecules (interleukin (IL)- $1 \beta$, IL-6, IL-8, IL-10, IL-12p70, and tumor necrosis factor (TNF)- $\alpha$ ) were measured as previously described. ${ }^{11}$ The concentration of histone $\mathrm{H} 3$ was determined in each vitreous sample by an enzyme-linked immunosorbent assay (ELISA). Briefly, polystyrene microtiter plates were coated with antihuman histone $\mathrm{H} 3$ polyclonal antibody, and the vitreous samples were added and incubated overnight at $2-8{ }^{\circ} \mathrm{C}$. The plates were washed three times, and the remaining binding sites were blocked with $1 \%$ BSA in phosphate-buffered saline (PBS). The plates were washed and subsequently incubated with the calibrator and samples for $24 \mathrm{~h}$ at room temperature. The plates were washed again, and an anti-human histone $\mathrm{H} 3$ peroxidase-conjugated polyclonal antibody (Abcam) was added and incubated for $2 \mathrm{~h}$ at room temperature. After another washing, the chromogenic substrate $3,3^{\prime}, 5,5^{\prime}$ tetra-methylbenzidine (Dojindo Laboratories, Kumamoto, Japan) was added to each well. The reaction was terminated by adding $0.35 \mathrm{~mol} / \mathrm{l} \mathrm{Na}_{2} \mathrm{SO}_{4}$, and the absorbance at $450 \mathrm{~nm}$ was determined with a microplate luminescence reader (BioRad, Hercules, CA, USA). The concentrations of six inflammatory cytokines and chemokines were measured using a cytometric bead array (CBA; BD Biosciences, San Diego, CA, USA). The assay was performed according to the manufacturer's instructions. The detection limits for IL-1 $\beta$, IL-6, IL-8, IL-10, IL-12p70, and TNF- $\alpha$ were 7.2, 2.5, 3.6, 3.3, 1.9, and $3.7 \mathrm{pg} / \mathrm{ml}$, respectively. All concentrations that were below the detection limit were assigned a value of 0 in the statistical analyses as previously described. ${ }^{11,14-16}$

\section{Animals and Induction of RD}

All experiments were performed in accordance with a statement describing the Use of Animals in Ophthalmic and Vision Research proposed by the Association for Research in Vision and Ophthalmology, and approval was obtained from our institutional Animal Care Committee. Brown Norway rats (Japan SLC, Shizuoka, Japan) were housed in covered cages and kept at a constant temperature and relative humidity with a regular 12:12-h light/dark schedule. Food and water were available ad libitum.

$\mathrm{RD}$ was induced in the rats as described in detail previously. ${ }^{10,11}$ Briefly, the rats were anesthetized with an intramuscular injection of ketamine and xylazine, and their pupils were dilated with topical $1 \%$ tropicamide and $2.5 \%$ phenylephrine hydrochloride. The retinas were detached by a subretinal injection of $1 \%$ sodium hyaluronate (Opegan; Santen, Osaka, Japan) with the anterior chamber punctured to reduce the intraocular pressure. The sclera was penetrated at the nasal equator with a 30-gauge needle. Then, sodium hyaluronate $(0.05 \mathrm{ml})$ was slowly injected into the subretinal 
space to enlarge the RD. RD was induced only in the right eye; the left eye was not touched and served as a control. Eyes with lens damage, vitreous hemorrhage, infection, or spontaneous reattachment were excluded from the analyses. A total of 30 rats were killed at 2 and 7 days after inducing the $\mathrm{RD}$ (15 animals at each time point). In some eyes, neutralizing polyclonal chicken IgY anti-histone H3 (antiH3) antibody (5 eyes, $20 \mu \mathrm{g} /$ eye) or isotype control $\mathrm{IgY}$ antibody (5 eyes, $20 \mu \mathrm{g} /$ eye) obtained from Shino-Test Corporation (Kanagawa, Japan) was injected into the subretinal space with hyaluronate. The doses were based on in vitro data. To determine the effect of these antibodies on retinal damage in eyes with $\mathrm{RD}$, the thickness of the retina between the internal limiting membrane and the external limiting membrane including the outer nuclear layer was measured in histological sections (three sections each point) stained with hematoxylin and eosin as previously described. ${ }^{11}$ Three separate measurements of the retinal thickness were obtained from each retinal section by using image analysis software, ImageJ (National Institutes of Health, Bethesda, MD, USA). The values were compared between the groups.

\section{Immunofluorescence Staining and Transmission Electron Microscopy}

The eyes were fixed in $4 \%$ paraformaldehyde at $4{ }^{\circ} \mathrm{C}$ overnight. The anterior segment and the lens were removed, and the remaining eye cup was cryoprotected with 10-30\% sucrose in PBS. The eye cups were then frozen in optimal cutting temperature compound (Sakura Finetech, Tokyo, Japan), and frozen sections were cut. The antibodies used for staining included rabbit polyclonal anti-histone $\mathrm{H} 3$ antibody $(2 \mu \mathrm{g} / \mathrm{ml})$ and mouse anti-CD68 monoclonal antibody (ED1, $0.6 \mu \mathrm{g} / \mathrm{ml}$ ). Normal rabbit IgG and normal mouse IgG were used in place of the primary antibody as a negative control in each case. The secondary antibodies were Alexa-Fluor 488conjugated goat anti-mouse IgG $\mathrm{F}(\mathrm{ab})_{2}$ fragment and AlexaFluor 594-conjugated goat anti-rabbit $\operatorname{IgG~} \mathrm{F}(\mathrm{ab})_{2}$ fragment (Molecular Probes, Carlsbad, CA, USA). The sections were incubated with the secondary antibody for $1 \mathrm{~h}$. Terminal deoxynucleotidyl transferase-mediated dUTP nick end-labeling (TUNEL) costaining was performed using an ApopTag Fluorescein In Situ Apoptosis Detection Kit according to the manufacturer's protocol (Chemicon, Temecula, CA, USA). ${ }^{17}$ The slides were counterstained with 4,6-diamidino-2phenylindole (DAPI), mounted with Shandon PermaFluor (Thermo Scientific, Waltham, MA, USA), and viewed with an Olympus fluorescence microscope (Olympus, Tokyo, Japan). Images were obtained using the same exposure time for each comparative section. Confocal laser scanning microscopy images were obtained with a Zeiss LSM700 confocal microscope (Zeiss, Thornwood, NY, USA). At least three sections from each eye were evaluated in all experiments.

To demonstrate the expression patterns of histone $\mathrm{H} 3$ in retinal cells under oxidative stress in vitro, R28 cells $\left(1 \times 10^{5}\right.$ cells/500 $\mu \mathrm{l}$ medium/well) were seeded on four-well glass coverslips and exposed or not exposed to $1 \mathrm{mM}$ hydrogen peroxide for $1 \mathrm{~h}$. The slides were fixed in $4 \%$ paraformaldehyde for $1 \mathrm{~h}$, permeabilized with precooled ethanol/acetic acid (2:1), and examined as described.

Transmission electron microscopy was performed as previously described. ${ }^{18}$ The eyes were enucleated, and the posterior segments were fixed in $1 \%$ glutaraldehyde and $1 \%$ paraformaldehyde in PBS. The detached retinas were removed and postfixed in veronal acetate-buffered osmium tetroxide $(2 \%)$, dehydrated in ethanol and water, and embedded in Epon. Ultrathin sections were cut and mounted on copper grids. The specimens were observed with a JEM 100CX electron microscope (JEOL, Tokyo, Japan).

\section{Cell Cultures}

Immortalized rat retinal precursor cell line, R28, was a kind gift from Dr GM Siegel (The State University of New York, Buffalo). The cells were cultured in high-glucose Dulbecco's modified Eagle's medium (DMEM) supplemented with 10\% fetal bovine serum (FBS), $10 \mathrm{mM}$ non-essential amino acids, and $10 \mathrm{mg} / \mathrm{ml}$ gentamicin as previously described. ${ }^{19}$ Human immortalized RPE cells (ARPE-19 cells) were obtained from the American Type Culture Collection (Manassas, VA, USA) and grown in DMEM/F12 supplemented with 10\% FBS, 2\% penicillin/streptomycin, and 1\% Fungizone (all chemicals were obtained from Invitrogen-Gibco, Rockville, MD, USA). Porcine primary PRE cells were isolated from the eyes of 5-6month-old pigs obtained from a local slaughterhouse as described in detail previously. ${ }^{20,21}$ Cells were cultured in $\alpha$ modified Eagle's medium with $2 \mathrm{mM}$ L-glutamine, $100 \mathrm{U} / \mathrm{ml}$ penicillin, and $100 \mathrm{mg} / \mathrm{ml}$ streptomycin (Sigma-Aldrich) at $37^{\circ} \mathrm{C}$ under $5 \% \mathrm{CO}_{2}$. The cells were cultured in $10 \% \mathrm{FBS}$ for the first $24 \mathrm{~h}$ and then switched to 5\% FBS. Cells at the second passage and $>90 \%$ confluence were used in all experiments. The cells were incubated at $37{ }^{\circ} \mathrm{C}$ in a $5 \% \mathrm{CO}_{2}$ incubator and subcultured with $0.05 \%$ trypsin-EDTA. Subconfluent cultures were trypsinized and seeded for the subsequent experiments.

\section{Cell Viability Assay}

Cell viability was assessed using a Cell Counting Kit-8 (Dojindo Laboratories) as previously described. ${ }^{18}$ This assay is based on the cleavage of 2-(2-methoxy-4-nitrophenyl)-3(4-nitrophenyl)-5-(2,4-disulfophenyl)-2H-tetrazolium, monosodium salt (WST-8) to formazan dye by the mitochondrial dehydrogenase enzyme. Briefly, R28 cells were cultured in 24-well plates $\left(1 \times 10^{5}\right.$ cells $/ 500 \mu \mathrm{l}$ medium/well $)$ with or without $1 \mathrm{mM}$ hydrogen peroxide for $1 \mathrm{~h}$. Subsequently, the cells were incubated with WST- 8 for $2 \mathrm{~h}$ at $37^{\circ} \mathrm{C}$, and the absorbance was measured at $450 \mathrm{~nm}$ with a microplate reader. ARPE-19 cells, porcine primary RPE cells, and R28 cells were also exposed to histones for $18 \mathrm{~h}$. To determine the role of TLRs in cell death induced by histones, the neutralizing mouse antibodies against TLR2 or TLR4 
were coincubated $(20 \mu \mathrm{g} / \mathrm{ml}$, eBioscience). Nonimmunized mouse IgG2 was used as controls.

\section{Lactate Dehydrogenase (LDH) Analysis for Necrosis}

The release of LDH into the media was measured with the LDH Cytotoxicity Detection Kit (Takara, Ohtsu, Japan) following the manufacturer's instructions. The level of LDH release was normalized to the total $\mathrm{LDH}$ content following cell lysis in a medium containing $0.9 \%$ Triton X-100. The absorbance was determined at $490 \mathrm{~nm}$ using a Multimode Microplate Reader.

\section{Flow Cytometry Analysis for Apoptosis}

The percentage of early apoptotic cells was determined with the ANNEXIN V-FITC Apoptosis Detection Kit (PN IM3546-200 tests; Beckman Coulter, Fullerton, CA, USA). After stimulation by histones, R28 cells were collected, washed with PBS, and resuspended in $100 \mu \mathrm{l}$ of binding buffer. The cells were double-labeled with Annexin V-FITC solution (1:20) for the assessment of phosphatidylserine exposure and with propidium iodide (PI, 1:20) for cell viability analysis. After $15 \mathrm{~min}$ of incubation in the dark, the cells were exposed to $400 \mu \mathrm{l}$ of binding buffer. The samples were analyzed in a flow cytometer (Beckman Coulter), and the data were collected. A total of 3000 events/sample were acquired, and Annexin V-positive and PI-negative events were defined as early apoptotic cells.

\section{Cytokine and Chemokine Analysis and Signaling Pathways in ARPE-19 Cells}

To measure the secretion of cytokines and chemokines, ARPE19 cells were cultured in complete medium in 24-well plates $\left(1 \times 10^{5}\right.$ cells $/ 500 \mu \mathrm{l}$ medium/well $)$ for $24 \mathrm{~h}$. Subsequently, the medium was replaced with medium lacking FBS, and after $4 \mathrm{~h}$ the cells were stimulated with histones for $18 \mathrm{~h}$. The medium was then collected, and the cytokine and chemokine levels were measured by CBA as described above.

The MAPK pathways have been implicated as key regulators that activate transcription factors, including NF- $\kappa \mathrm{B}$, and the production of proinflammatory cytokines. ${ }^{21,22}$ To investigate the relationship between MAPKs and cytokine secretions, the cells were serum-starved for $4 \mathrm{~h}$, and kinase inhibitors (U0126, SB203580, or SP600125) were individually added to the medium for $1 \mathrm{~h}$ before stimulation with histones. Neither the concentrations of the inhibitors nor the presence of dimethyl sulfoxide affected the ARPE-19 cell viability as determined by the WST- 8 assay (data not shown) and by earlier reports. ${ }^{23,24}$ The assays were performed in triplicate, and three independent experiments were carried out.

Western Blot Analysis of Histone H3 or MAPK Activation We prepared $50 \mu \mathrm{g} / \mathrm{ml}$ histones in a medium containing PBS or porcine vitreous, and samples from each group were collected. The samples were lysed in sodium dodecyl sulfate (SDS) sample buffer, and equal volumes of protein extracts were loaded onto 10-20\% SDS-polyacrylamide gels before transfer onto a nitrocellulose membrane. The membrane was exposed to anti-histone $\mathrm{H} 3$ antibody (1:4000; Abcam) overnight at $4{ }^{\circ} \mathrm{C}$, and the blots were subsequently probed with anti-rabbit secondary antibodies conjugated to horseradish peroxidase (1:3000). The images were developed using the enhanced chemiluminescence system (GE Healthcare, Tokyo, Japan).

To analyze the activation of MAPKs after stimulation by histones, ARPE-19 cells $\left(5 \times 10^{5}\right)$ were subcultured on $6-\mathrm{cm}$ tissue culture dishes. The cells were serum-starved in DMEM/F12 and stimulated with $10 \mu \mathrm{g} / \mathrm{ml}$ histones for the selected times. The activation of the ERK-1/2, p38, and JNK pathways was also analyzed by western blots. The membrane was reacted with phospho-ERK-1/2, phospho-p38, and phospho-JNK (1:1000; Cell Signaling Technology, Beverly, MA, USA). After detection, the blots were stripped and reprobed with an antibody against total ERK-1/2, total p38, and total JNK (1:1000; Cell Signaling Technology) as previously described. ${ }^{10,11}$

\section{Effect of Vitreous on Toxicity of Histones}

Fresh porcine eyes were purchased from a local slaughterhouse. Permission was obtained from the slaughterhouse and from the University to use these eyes for research. The anterior segment containing the lens was removed, and the vitreous body was separated from the eye cup. After washing 3 times with PBS, the vitreous was passed through an injection syringe $(2.5 \mathrm{ml})$ with 19 -gauge and 23 -gauge needles several times to mix it with serum-free medium in a volume ratio of 1:1 based on the procedures described previously. ${ }^{25}$ ARPE-19 cells were incubated with the mixed medium containing vitreous for $18 \mathrm{~h}$ in the presence or absence of histones. The concentrations of cytokines and chemokines in the incubation media were determined, and the degree of cell viability was analyzed. Similar experiments were performed on porcine primary RPE cells and R28 cells. To examine the degree of cytotoxicity of histones on ARPE19 cells, we used the Cell Stain Double Staining Kit (Dojindo Laboratories). After stimulating the cells as described, they were incubated for $30 \mathrm{~min}$ with $2 \mu \mathrm{M}$ PI and $1 \mu \mathrm{M}$ calcein acetoxymethyl ester (calcein-AM). Subsequently, the cells were rinsed and examined by fluorescence microscopy (Model BZ-9000; Keyence, Osaka, Japan). Calcein-AM labels viable cells and PI labels only cells with plasma membrane damage and accumulates in the nucleus.

\section{Effect of Hyaluronidase and Hyaluronan}

The isolated vitreous was pretreated with bovine testes hyaluronidase (H3506, Sigma-Aldrich) in serum-free medium. The final concentration of hyaluronidase was $1 \mathrm{mg} / \mathrm{ml}$, as determined by earlier studies. ${ }^{26,27}$ After starving the ARPE19 cells in the hyaluronidase-treated medium containing vitreous for $4 \mathrm{~h}$, the cells were cultured with or without histones. The direct effect of hyaluronan was also evaluated. 
After serum-starving the ARPE-19 cells for $4 \mathrm{~h}$, they were incubated with or without hyaluronan (Opegan high, Santen; volume ratio, medium/hyaluronan $=4: 1$, and with or without histones, and the effect was evaluated as above. Similar experiments were also performed in porcine primary RPE cells and R28 cells.

\section{Statistical Analyses}

In each group, the concentrations of histone $\mathrm{H} 3$ and the inflammatory cytokines and chemokines in the vitreous were compared using a one-way analysis of variance (ANOVA) with Scheffe's F-test. The correlations between the concentrations of inflammatory cytokines and chemokines in the vitreous samples were analyzed by simple linear regression analysis and Spearman's rank correlation coefficient. All in vitro and in vivo data are presented as mean values \pm s.e.m. Student's $t$-tests were used to compare two groups, and one-way ANOVA followed by post hoc Dunnett test was used to compare the findings obtained with the experiment to those obtained with the control. A $P$-value of $<0.05$ was considered significant.

\section{RESULTS}

\section{Histone H3 Levels in the Vitreous of Eyes with RD}

To investigate the role of extracellular histones in ocular diseases, we quantified the concentration of histone $\mathrm{H} 3$, a highly toxic and readily detectable component of the histone family, ${ }^{4}$ in the vitreous of eyes with different diseases, for example, epiretinal membrane (ERM), macular hole $(\mathrm{MH})$, rhegmatogenous RD (RRD), proliferative diabetic retinopathy (PDR), and proliferative vitreous retinopathy (PVR)).

The average age and the distribution of the sexes were not significantly different among the different groups (Table 1). The concentration of histone $\mathrm{H} 3$ was $30.92 \mathrm{ng} / \mathrm{ml}$ in the vitreous of eyes with RRD, and this was significantly higher than the $0.00 \mathrm{ng} / \mathrm{ml}$ observed in eyes with $\mathrm{MH}(P<0.05)$. The concentration of histone $\mathrm{H} 3$ in eyes with $\mathrm{RRD}$ was not significantly different from that in eyes with ERM $(1.96 \mathrm{ng} / \mathrm{ml})$, and the difference between eyes with $\mathrm{MH}$ and ERM was also not significant (Figure 1a).

We examined the relationship between the vitreous histone $\mathrm{H} 3$ concentration and the duration of RRD within a range of 5-60 days, and we also examined the extent of RRD within a range of 0.5 to 4 quadrants (Table 2). Simple linear regression showed that the vitreous histone $\mathrm{H} 3$ concentration in eyes with RRD was not correlated with the duration of the RRD $(r=0.55, P=0.06)$ or the extent of the RRD $(r=0.33$, $P=0.27)$. The Spearman's rank correlation coefficient was $r=0.22(P=0.54)$ for the duration of the RRD and $r=0.44$ $(P=0.18)$ for the extent of the detachment.

In addition, the concentration of histone $\mathrm{H} 3$ in the vitreous was not significantly correlated with the concentrations of IL-6 $(r=0.13, P=0.66)$ or IL-8 $(r=0.22, P=0.46)$ as determined by simple regression. The Spearman's rank correlation coefficient was $r=0.09(P=0.93)$ for IL-6 and $r=0.06(P=0.98)$ for IL-8 (Figures $1 \mathrm{~b}$ and $\mathrm{c}$ ). These findings indicate that histone $\mathrm{H} 3$ is present in the vitreous of eyes with $\mathrm{RRD}$; however, its concentration is not significantly correlated with the intravitreal levels of IL-6 and IL-8.

\section{Histones Are Released Extracellularly by Oxidative Stress}

Next, we evaluated the expression patterns and cellular distribution of histone $\mathrm{H} 3$ in $\mathrm{R} 28$ cells in the presence or absence of oxidative stress. Excess reactive oxygen species can lead to the destruction of cellular components and ultimately induce cell death through apoptosis or necrosis. To induce oxidative stress, we used a toxic dose $(1 \mathrm{mM})$ of hydrogen peroxide, as described previously. ${ }^{10}$ We found that histone H3 immunoreactivity was stable in the nucleus of unstimulated R28 cells (Figure 2a). In contrast, at $1 \mathrm{~h}$ after exposure to hydrogen peroxide, the cells had high levels of histone $\mathrm{H} 3$ in their cytoplasm compared with those that were not stressed. Exposure to hydrogen peroxide $(1 \mathrm{mM})$ for $24 \mathrm{~h}$ led to the death of $\sim 90 \%$ of the cells (Figure $2 \mathrm{~b}$ ) and induced a massive release of histone $\mathrm{H} 3$ from the cells into the supernatant (Figure 2c). These results indicate that nuclear histone $\mathrm{H} 3$ can be increased by oxidative stress and can be released from cells. The degree of extracellular release of histone $\mathrm{H} 3$ in the eye was dependent on the extent of the cell death.

Histones Are Released from Rat Retinas after RD In Situ Because these findings indicate that histone $\mathrm{H} 3$ is associated with cell death, we investigated whether histone $\mathrm{H} 3$ was present in the rat retina, and we explored how the levels and

Table 1 Patient characteristics

\begin{tabular}{lccccr}
\hline Characteristics & ERM & MH & RRD & PDR & PVR \\
\hline Subjects, no. & 7 & 9 & 13 & 17 & 5 \\
Age (years) & $64(31-77)$ & $64(47-80)$ & $59(48-82)$ & $56(31-67)$ & $70(54-87)$ \\
Female sex, no. (\%) & $3(42)$ & $4(44)$ & $7(53)$ & $5(29)$ & $1(25)$
\end{tabular}

Values are expressed as the median (range) or number (\%).

${ }^{\text {a }}$ Scheffe's F-test.

${ }^{\mathrm{b}}$ The $\chi^{2}$ test. 

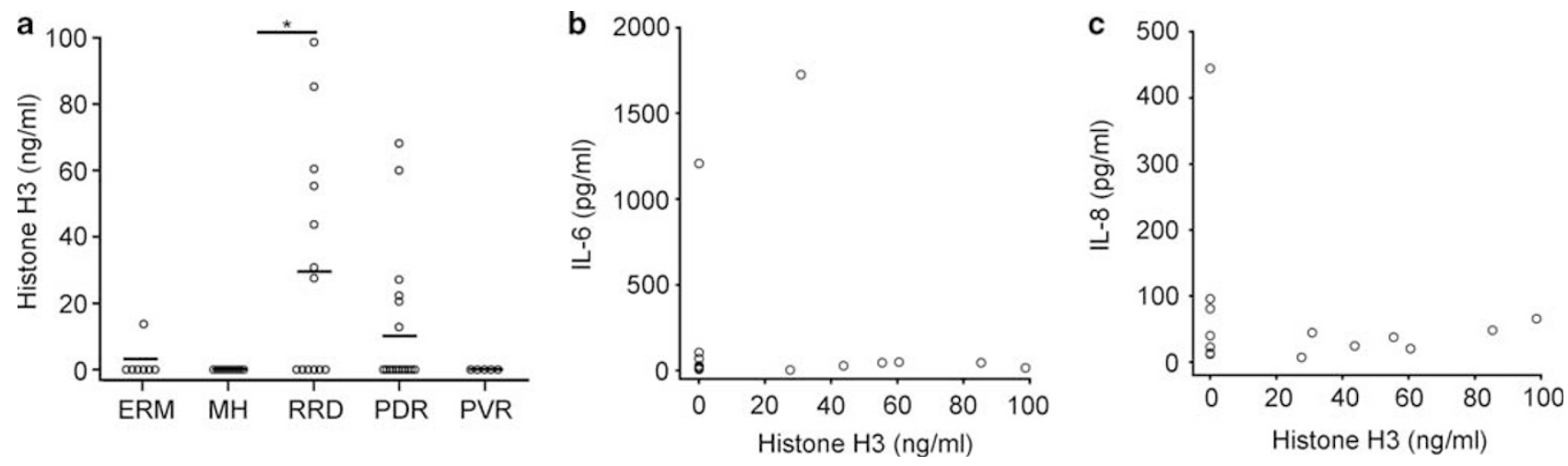

Figure 1 Levels of histone $\mathrm{H} 3$ in the vitreous. (a) Vitreous levels of histone $\mathrm{H} 3$ in eyes with epiretinal membrane (ERM), macular hole (MH), rhegmatogenous retinal detachment (RRD), proliferative diabetic retinopathy (PDR), and proliferative vitreoretinopathy (PVR). The vitreous histone H3 level in eyes with RRD was significantly higher than that in eyes with MH. Bars indicate average values. (b) Scatter plot of the vitreous level of histone H3 and IL-6 (simple linear regression, $r=0.13, P=0.66$; Spearman's rank correlation coefficient, $r=0.09, P=0.93$ ) in eyes with RRD. (c) Scatter plot of the vitreous level of histone $\mathrm{H} 3$ and IL-8 (simple linear regression, $r=0.22, P=0.46$; Spearman's rank correlation coefficient, $r=0.06, P=0.98$ ) in eyes with RRD. One-way ANOVA with Scheffe's F-test: ${ }^{*} P<0.05$.

Table 2 Clinical state of rhegmatogenous retinal detachment

Duration of disease (days)

$13(5-60)$

Extent of detached retina (quadrants)

$1.8(0.5-4)$

Values are expressed as the median (range).

localization of histones change after RD. Immunohistochemical studies showed that histones were strongly expressed in the normal control rat retina and colocalized with DAPI in the nuclei. Histone $\mathrm{H} 3$ staining in the normal rat retina was prominent in the nuclei of the ganglion cell layer, inner nuclear layer, outer nuclear layer, and RPE (Figures 3a, c, and e). In eyes with $\mathrm{RD}$, histone $\mathrm{H} 3$ immunoreactivity was observed in the subretinal space (Figures $3 b, d$ and $f$ ).

It has been reported that macrophages migrate into the subretinal space of eyes with RD. ${ }^{28}$ To determine whether this also occurs in the detached rat retina, we performed double immunofluorescence staining for histone $\mathrm{H} 3$ and ED-1. Some of the cells in the subretinal space were immunopositive for ED-1, indicating that they were macrophages or debris from the outer retina (Figures $3-\mathrm{j}$ ). In addition, some cells in the outer nuclear layer were TUNEL positive (Figure 3k). Electron microscopy showed that apoptotic and necrotic photoreceptor cells were present in the detached retina (Figure 31). These results indicate that histones are released into the extracellular space from dying photoreceptors because the retina is detached.

\section{Histones Cause Cytokine Production by ARPE-19 Cells}

It has been reported that extracellular histones are potent inducers of proinflammatory cytokines. ${ }^{5,6}$ We showed that the levels of intravitreal IL-6 and IL-8 were significantly higher in eyes with a RRD compared with control eyes. ${ }^{10,11,14}$ To confirm this, we exposed R28 cells and ARPE-19 cells to histones and measured cytokines in the supernatants. The results indicated that the concentrations of IL- 6 and IL-8 were less than the detectable level at the baseline in R28 cells, and their concentrations did not increase after exposure to histones (data not shown). On the other hand, the concentrations of IL- 6 and IL-8 were significantly increased in ARPE-19 cells after exposure to histones (Figures $4 \mathrm{a}$ and b). However, no significant increase was observed in IL-1 $\beta$, IL-10, IL-12p70, or TNF- $\alpha$ in ARPE-19 cells.

When heat-inactivated histones were used to eliminate the possibility of contamination by lipopolysaccharides (LPS), the increase in IL-8 was completely blocked (Figure 4c). In addition, our measurements showed that the LPS concentration was $<10 \mathrm{pg}$ in $1 \mathrm{mg}$ of histones. Thus, the above findings were not induced by LPS contamination, but they were likely caused by the histones.

\section{Induction of IL-8 by Histones is Mediated by ERK1/2- and p38 Kinase-Dependent Pathways and TLR4 in ARPE-19 Cells}

The MAPKs have been implicated as being key regulators of the production of proinflammatory cytokines. ${ }^{29}$ The extracellular signal-regulated kinases (ERKs) and p38 MAPK are two major classes of MAPKs that play important roles in transducing inflammatory signals. ${ }^{30,31}$ To determine whether these two pathways are involved in the upregulation of IL-6 and IL-8 in ARPE-19 cells, we examined the activation of signaling molecules by western blotting with phospho-specific antibodies. The results showed that ERKs, p38 MAPK, and JNK were all phosphorylated by the histones (Figure 5a).

Kinase inhibitors were used to investigate the roles of the signaling pathways and the cytokine levels. We used U0126 as an inhibitor of the ERK1/2 pathway, SB203580 as an inhibitor of the p38 MAPK pathway, and SP600125 as an inhibitor of the JNK pathway. The induction of IL-8 was inhibited by U0126 and SB203580 but not by SP600125 (Figure 5b). 

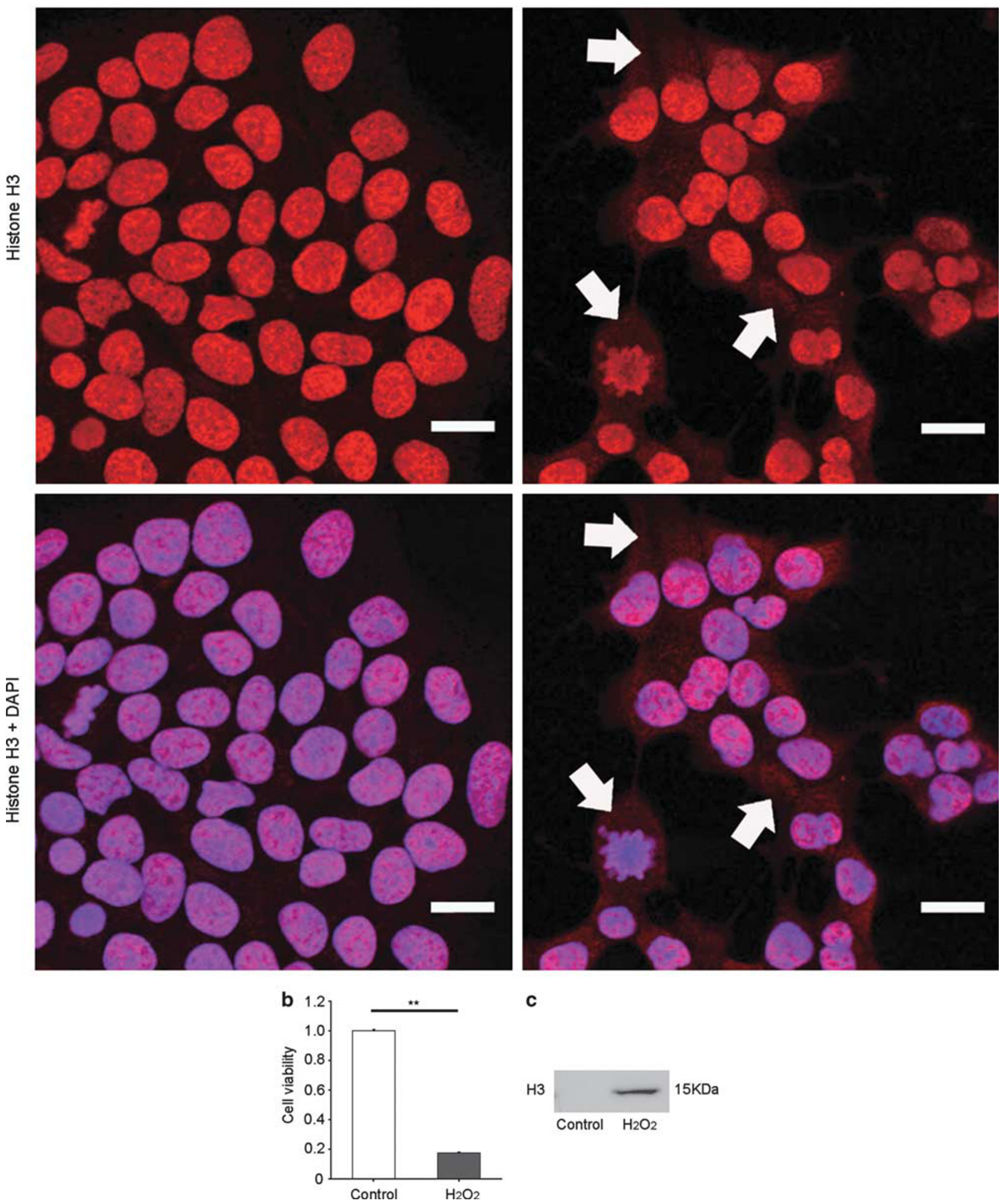

C

H3

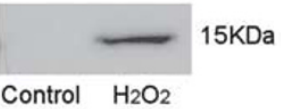

Figure 2 Release of histone H3 from R28 retinal neuronal cells under oxidative stress. (a) Immunofluorescent photomicrographs showing anti-histone $\mathrm{H} 3$ antibody (red) and DAPI (blue). Histone $\mathrm{H} 3$ was predominantly present in the nuclei of unstimulated R28 cells (left column). Histone H3 relocalized into the cytoplasm $1 \mathrm{~h}$ after exposure to a toxic dose of hydrogen peroxide $(1 \mathrm{mM})$. Scale bars: $10 \mu \mathrm{m}$. (b) After $24 \mathrm{~h}$ of exposure to $1 \mathrm{mM}$ hydrogen peroxide, the cell viability was decreased to $\sim 10 \%$ of the control as determined by a WST-8 assay. (c) The massive release of histone H3 into the culture supernatant was determined by western blot analysis after application of the treatment described in (b). Similar results were obtained from three independent experiments. The data are presented as mean \pm s.e.m., $n=4$. Student's $t$-test: ${ }^{*} P<0.01$. 

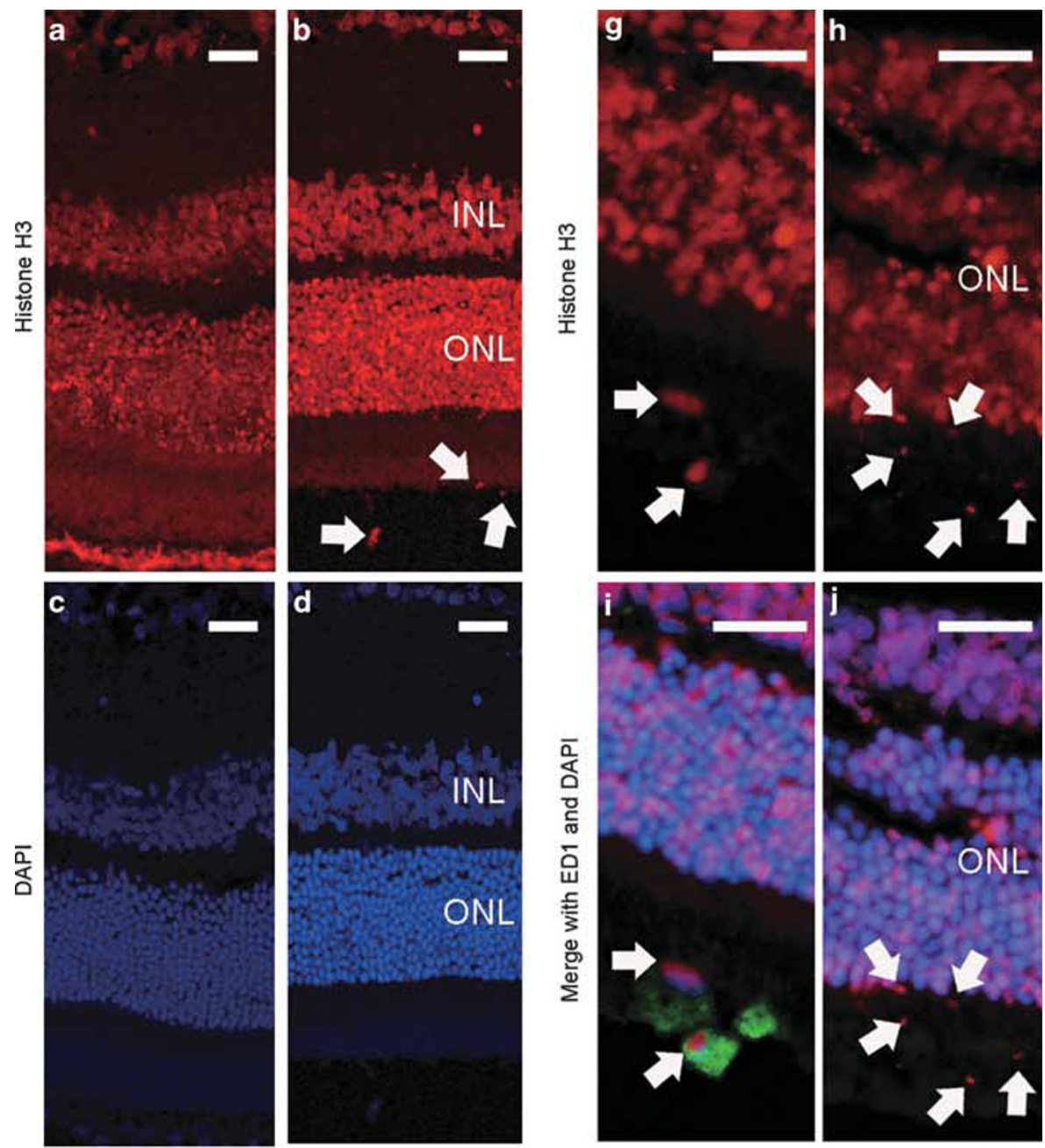

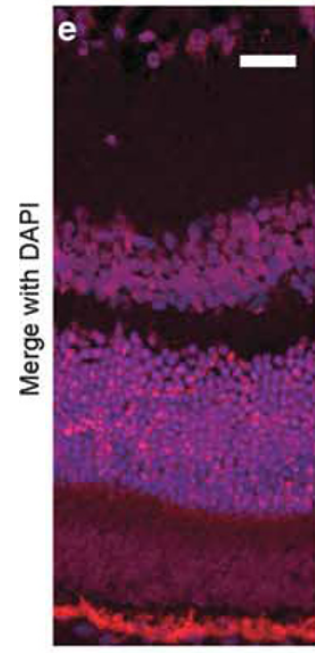

RD (-)

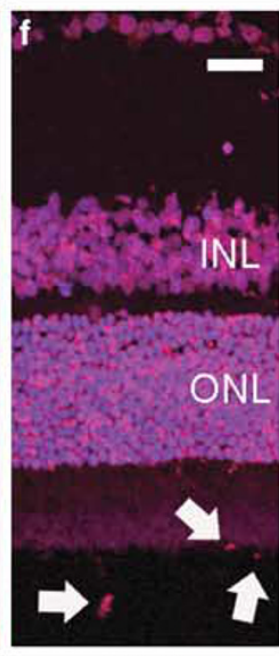

RD (+)
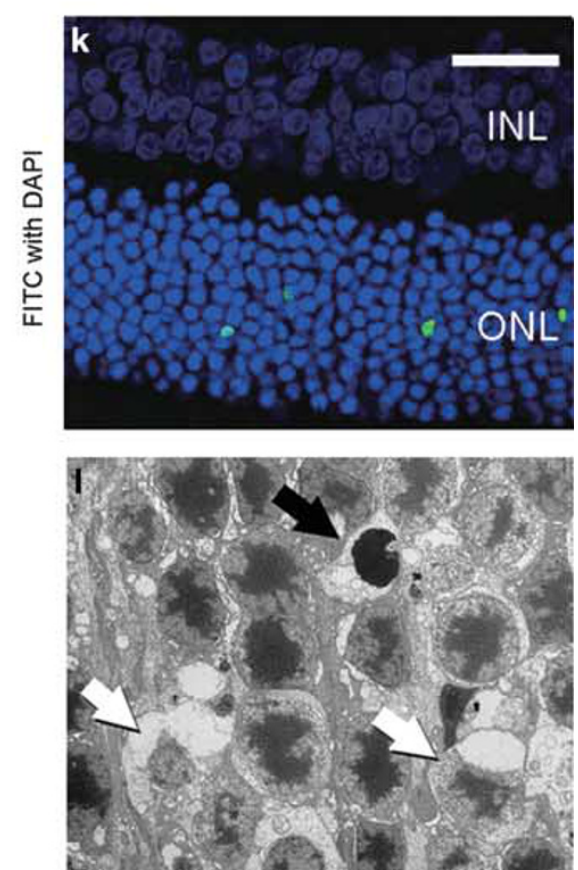
TLR4 protein was detected in ARPE-19 cells (data not shown), and a neutralizing antibody against TLR4 significantly reduced the increase of IL- 8 production. However, IL- 8 production was not affected by a neutralizing antibody against TLR2 or nonimmunized IgG (Figure 5c). Therefore, the effect on IL-8 might be partially mediated through TLR4.

\section{Excessive Histones Cause Cell Death}

We have shown the presence of apoptotic photoreceptor nuclei in the detached retina ${ }^{10,11}$ that may be related to the findings that histones can cause cellular damage. Abrams et $a l^{31}$ demonstrated that extracellular histones bind to phospholipids, disrupt cell membranes, and cause calcium influx. $^{28}$ Exposure to histones also increases necrosis and apoptosis in renal endothelial and tubular cells. ${ }^{32}$ Based on these findings, we investigated whether histones induced apoptosis or necrosis in retinal and RPE cells.

Annexin V/PI analysis by flow cytometry showed that the number of cells showing early apoptosis, defined as an increase in the Annexin V-positive/PI-negative cells, was increased after exposure to $50 \mu \mathrm{g} / \mathrm{ml}$ histones (Figures 6a and b) on R28 cells. In addition, the number of PI-positive cells also increased in a dose- and time-dependent manner within $18 \mathrm{~h}$. In ARPE-19 cells, cell viability was decreased and $\mathrm{LDH}$ release was increased in the presence of more than $20 \mu \mathrm{g} / \mathrm{ml}$ histones (Figures $6 \mathrm{c}$ and $\mathrm{d}$ ). The cytotoxic effect was not inhibited by coincubation with anti-TLR2 or anti-TLR4 antibodies (Figure 6e).

To further explore the role of histones in $\mathrm{RD}$, some rats received a subretinal injection of anti-histone antibodies or nonimmunized control antibody. At 2 days after RD, there were no apparent morphological differences between the antibody-injected animals and controls. However, at 7 days after RD, there was a thinning of the ONL because of photoreceptor cell loss and deconstruction of the inner and outer segments of the photoreceptors. The ratio of the thickness of the ONL to the entire retina differed significantly between the anti-histone $\mathrm{H} 3$ antibody group $(0.314 \pm 0.012)$ and the no-antibody-injected group $(0.211 \pm 0.015, P<0.01)$ or between the anti-histone $\mathrm{H} 3$ antibody group and the control IgY group $(0.240 \pm 0.018, P<0.01)$. No significant difference was found between the no-antibody-injected group and the control IgY group (Figures 6f and g). These findings suggest that histones play a specific role in the photoreceptor damage in RD.

\section{Histone Neutralization by Vitreous Body and Role of Hyaluronan}

Our findings showed that the intravitreal level of histone $\mathrm{H} 3$ was high in eyes with RD. However, the retinal and RPE cells were not necessarily damaged, and the intravitreal cytokine levels were not significantly correlated with the intravitreal
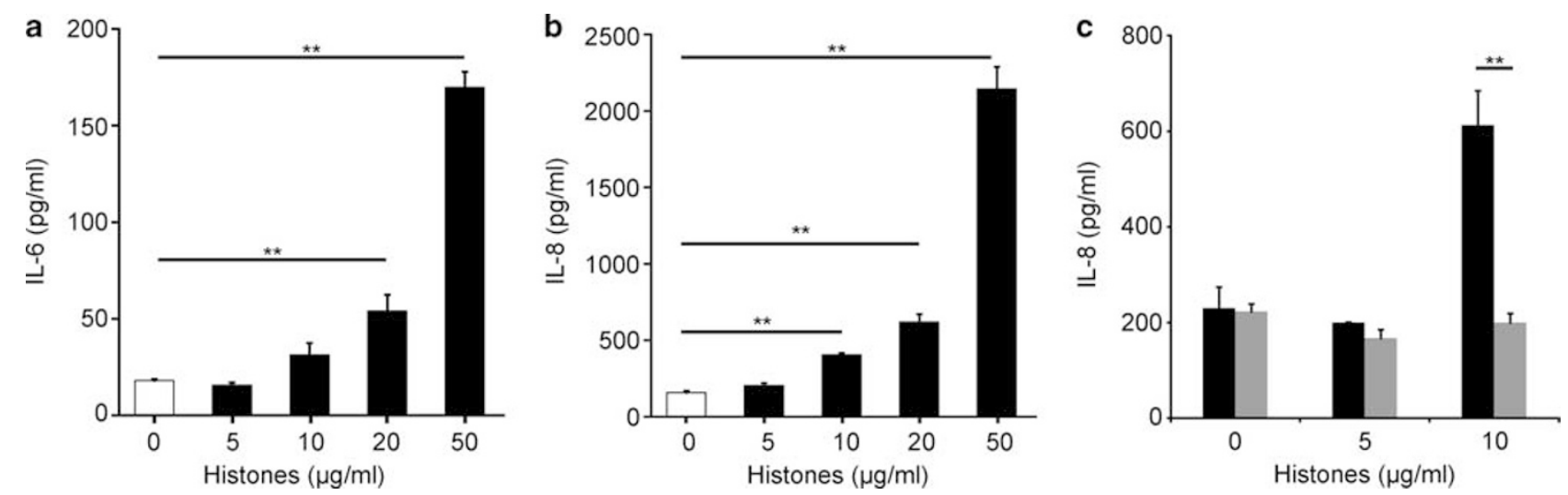

Figure 4 Effects of histones on cytokine production in ARPE-19 cells. IL-6 (a) and IL-8 (b) levels in the conditioned medium of ARPE-19 cells after histone stimulation. The expression of both IL- 6 and IL-8 was upregulated by histones in a dose-dependent manner. (c) Stock solution of 10 mg/ml of histones was boiled for $1 \mathrm{~h}$. ARPE-19 cells were treated with histones or boiled histones for $18 \mathrm{~h}$. IL-8 production was abolished with heat-inactivated histones. Black bars: nonboiled histones, gray bars: boiled histones. The experiments were performed in triplicate. The data are presented as the mean \pm s.e.m., $n=4$. One-way ANOVA followed by post hoc Dunnett test was performed for comparison with the control: ** $P<0.01$.

Figure 3 Immunofluorescence analysis of histone $\mathrm{H} 3$ in a rat model of RD. Anti-histone $\mathrm{H} 3$ immunostaining in a control eye (a, c, e) and an eye with $\mathrm{RD}(\mathbf{b}, \mathbf{d}, \mathbf{f})$. Histone H3-positive reaction (red) was mainly observed in the nucleus; however, histone H3-positive fragments were observed in the outer segments and subretinal space of eyes with RD (b, d, f, arrows). Enlarged image of the outer segment of a detached retina ( $\mathbf{g}$, h, i, j, $\mathbf{k}$ ). Histone H3positive fragments were observed in the nucleus of ED1-positive macrophages (i, green cells and arrows). Although histone H3-positive/ED-1-negative fragments were also present outside of the retina (h, j, arrows), the debris appeared to originate from the outer retina. (k) TUNEL-positive staining was frequently observed in the outer nuclear cell layer of the detached retina. Scale bars: $25 \mu \mathrm{m}$. (I) Transmission electron microscopy of a detached retina. Apoptotic (black arrow) and necrotic (white arrow) cells were observed (original magnification, $\times 2000$ ). INL, inner nuclear layer; ONL, outer nuclear layer. 
a
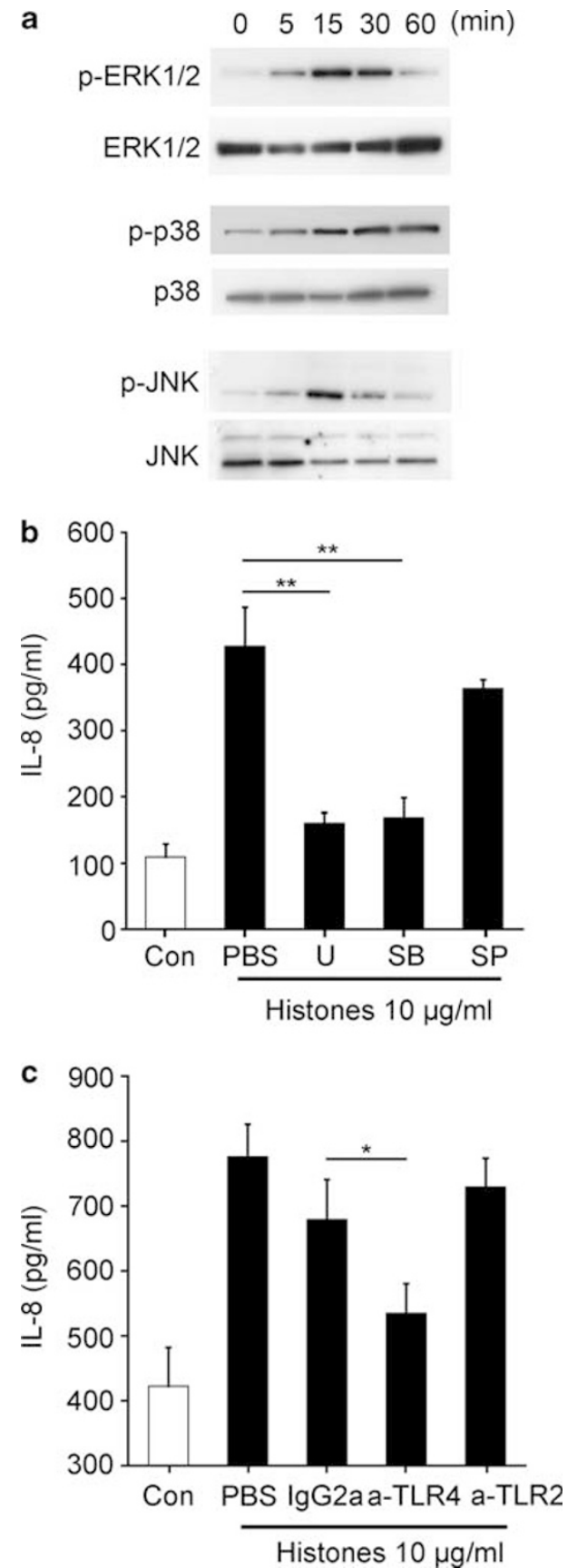

Figure 5 Effects of a kinase inhibitor and a TLR-neutralizing antibody on histone-induced cytokine production in ARPE-19 cells. (a) Histones induced the phosphorylation of ERK1/2, p-38 MAPK, and JNK. ARPE-19 cells were stimulated with $10 \mu \mathrm{g} / \mathrm{ml}$ histones for $5,15,30$, or $60 \mathrm{~min}$. (b) ARPE-19 cells were stimulated with histones $(10 \mu \mathrm{g} / \mathrm{ml})$ with or without preincubation with MAPK inhibitors. Histone-induced IL-8 production was significantly decreased with ERK1/2 and p-38 MAPK inhibitors. (c) ARPE-19 cells were stimulated with histones $(10 \mu \mathrm{g} / \mathrm{ml})$ with or without preincubation with neutralizing monoclonal antibodies (mAbs) against TLR2, TLR4, or a control antibody. Histone-induced IL-8 production was significantly decreased with anti-TLR4. The experiments were performed in triplicate. The data are presented as mean \pm s.e.m., $n=4$. Student's $t$-tests: ${ }^{*} P<0.05 ;{ }^{* *} P<0.01 . \mathrm{U}=10 \mu \mathrm{M}$ U0126,

$\mathrm{SB}=10 \mu \mathrm{M}$ SB203580, SP $=1 \mu \mathrm{M}$ SP600125. histone $\mathrm{H} 3$ level. These results indicated that the eye must have some protective mechanism against the toxicity of histones.

We hypothesized that the vitreous has a neutralizing effect on histones. To test this hypothesis, we added histones to the vitreous and ARPE-19 cell culture medium. Our findings showed that the vitreous formed aggregates in which histones were sequestered (Figures $7 \mathrm{a}-\mathrm{c}$ ). To determine the location of histone $\mathrm{H} 3$, we prepared media containing $\mathrm{PBS}$ or porcine vitreous. After the addition of histones $(50 \mu \mathrm{g} / \mathrm{ml})$, western blotting was performed. Our results showed that the histones were predominantly present in the aggregated vitreous and were not detectable in the nonaggregated vitreous (Figures $7 \mathrm{~b}$ and $\mathrm{c}$ ).

Next, we determined the effect of the vitreous on ARPE-19 cells stimulated by histones. Histones were toxic to ARPE-19 cells, but the toxicity was completely blocked by the addition of vitreous (Figure 8a). Histones increased the production of IL-6 and IL-8 in a dose-dependent manner, but this was significantly inhibited by the addition of vitreous (Figures $8 \mathrm{~b}$ and c). In porcine primary RPE cells and R28 cells, cell viability was also reduced in a dose-dependent manner after exposure to histones and this effect was also cancelled by coincubation with vitreous (Figures $8 \mathrm{~d}$ and e).

Calcein-AM and PI staining showed that the addition of vitreous alone did not cause cell death (Figures 9a-c), but histones without vitreous damaged almost all the cells (Figures 9d-f). After adding histones to a medium containing vitreous, the cell damage was limited only to the areas where aggregated histones attached to the cells. No damaged cells were observed in areas that were not in contact with the aggregates (Figures 9g, h, and i).

Because hyaluronan is a major component of the vitreous, the vitreous was pretreated with hyaluronidase before histone challenge. Under these conditions, the formation of aggregated clusters was significantly inhibited (Figure 10a), and the damage to ARPE-19 cells was limited to areas where a histone cluster was present (Figure 10b). Thus, the damaged area was more diffusely extended with hyaluronidasepretreated vitreous than with basic vitreous.

We found that when the histones were mixed with hyaluronan, aggregated clusters similar to vitreous clusters were formed (Figure 10c). In addition, ARPE-19 cells incubated with histones in the presence or absence of hyaluronan showed that the cell damage as well as IL- 6 and IL- 8 production induced by histones were significantly rescued by hyaluronan (Figures 10d-f). In porcine primary RPE cells and R28 cells, cell viability was also reduced in a dose-dependent manner after exposure to histones, and this effect was also cancelled by coincubation with hyaluronan (Figures $10 \mathrm{~g}$ and $\mathrm{h}$ ). Furthermore, phosphorylation of ERK1/2, p38, or JNK was induced by histones, but not after coincubation with hyaluronan or hyaluronan alone (Supplementary Figure S1).

Therefore, hyaluronan can inhibit the effects of histones. It is likely that hyaluronan in the vitreous forms aggregated 
a

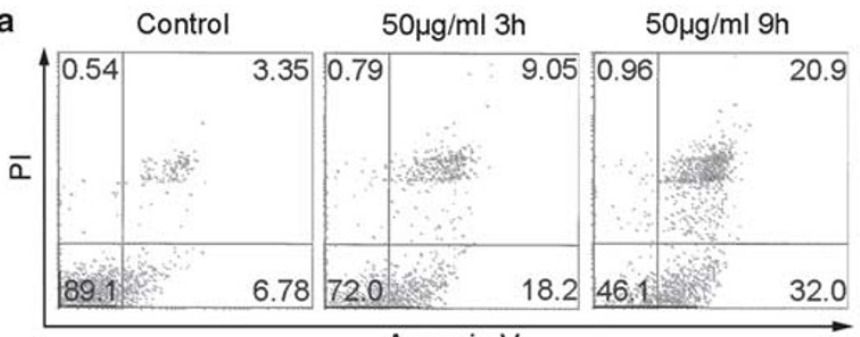

Annexin V

c

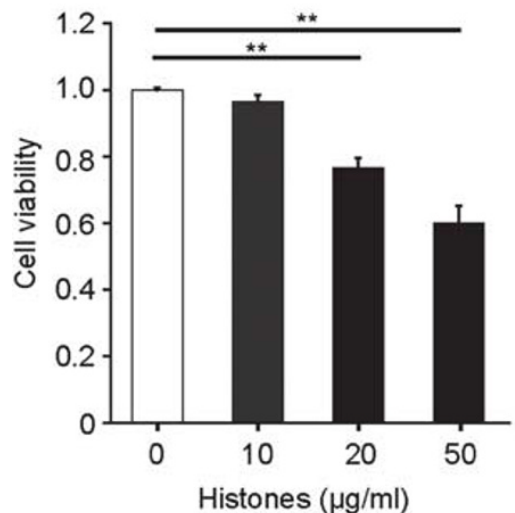

d

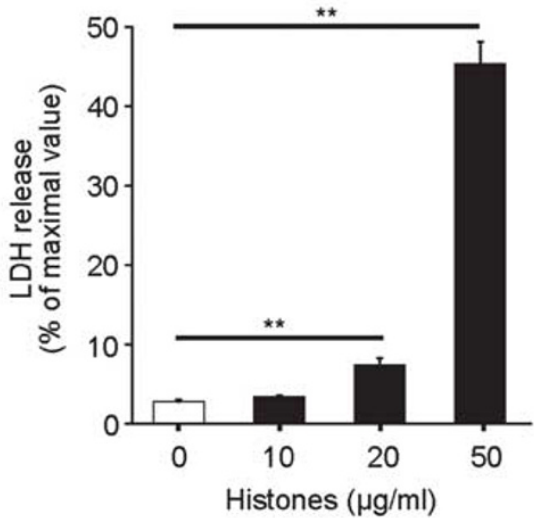

f

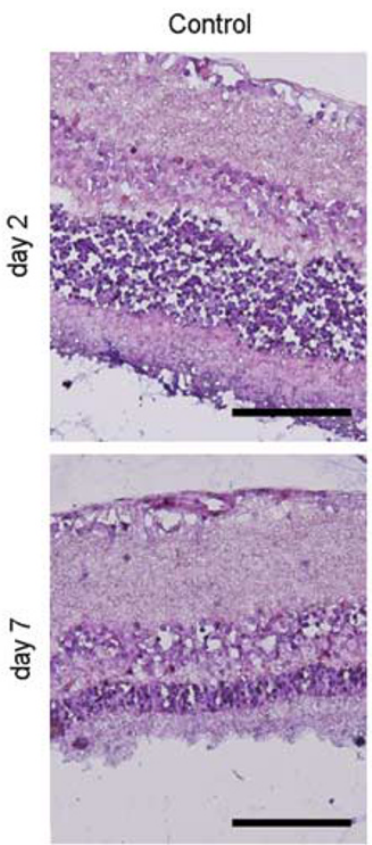

anti-H3 $\mathrm{Ab}$

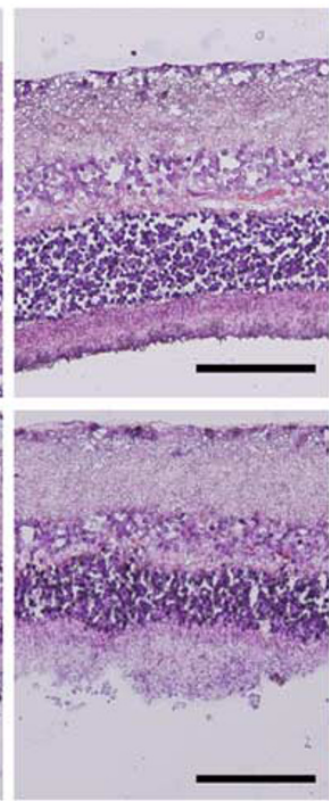

Control Ab

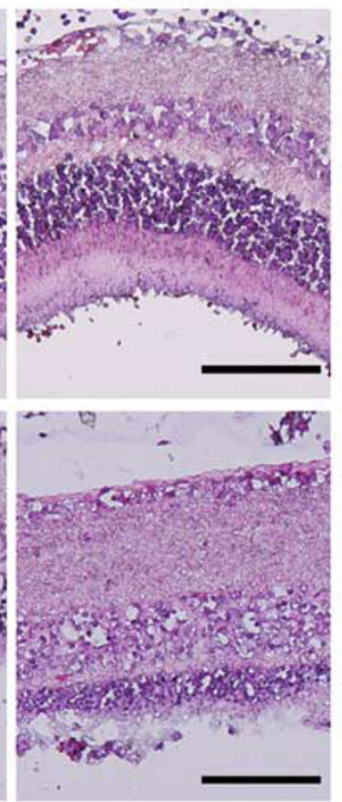

b

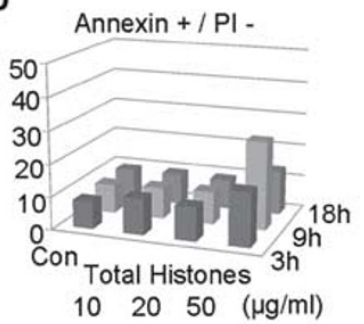

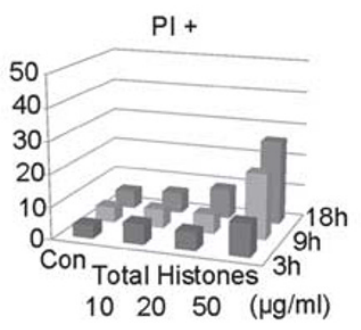

e g

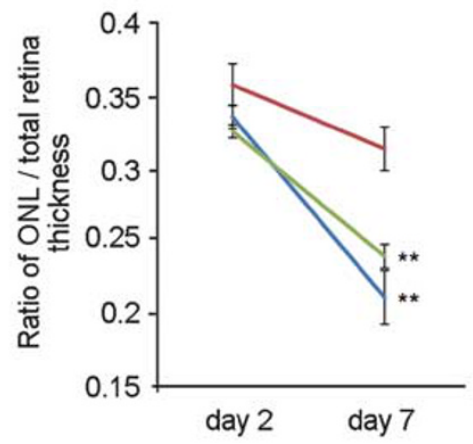

Control
anti-H3 Ab -
Control Ab

Figure 6 Cytotoxicity of histones and effect of anti-H3 antibody on retinal ONL thickness in RD models. (a) Flow cytometric analysis of apoptotic populations after stimulating R28 cells with histones. The cells were stained with Annexin V and PI. The percentages of Annexin V-positive and PInegative early apoptotic cells were $8.4 \pm 0.9 \%$ in controls, $16.5 \pm 0.8 \%$ in cells treated with $50 \mu \mathrm{g} / \mathrm{ml}$ histones for $3 \mathrm{~h}$, and $27.0 \pm 3.6 \%$ in cells treated with $50 \mu \mathrm{g} / \mathrm{ml}$ histones for $9 \mathrm{~h}$. (b) The data are presented as the mean percentage of Annexin V-positive/PI-negative cells and PI-positive cells. PI, propidium iodide. (c) After $18 \mathrm{~h}$ of exposure to histones, the viability of ARPE-19 cells was significantly decreased compared with the control as determined by a WST-8 assay. (d) Compared with the controls, exposure of ARPE-19 cells to histones for $18 \mathrm{~h}$ resulted in a significant increase in cell death (LDH release). (e) The cytotoxic effect of histones to ARPE-19 cells was not inhibited by coincubation with anti-TLR2 or anti TLR4 antibodies. (f) Effect of anti-histone $\mathrm{H} 3$ (anti-H3) antibody on retinal thickness. Anti-H3 Ab or control Ab was injected into the subretinal space with hyaluronate. No apparent morphological differences were observed among the three groups on day 2 after RD. By day 7 after the RD, the ONL thickness in anti-H3 Ab-injected eyes was significantly thicker than that of the normal controls or control Ab-injected eyes. Scale bars: $100 \mu \mathrm{m}$. (g) Graph summarizing the effects of intravitreal injection on the ONL thickness of rat retinas at 2 and 7 days after the detachment. ${ }^{* *} P<0.01$; normal controls and control $\mathrm{Ab}$ versus anti-H3 $\mathrm{Ab}$ injection at day 7. The experiments were performed in triplicate. The data are presented as mean \pm s.e.m., $n=4$. One-way ANOVA followed by post hoc Dunnett test was performed for comparison with the control: **P $<0.01$. 

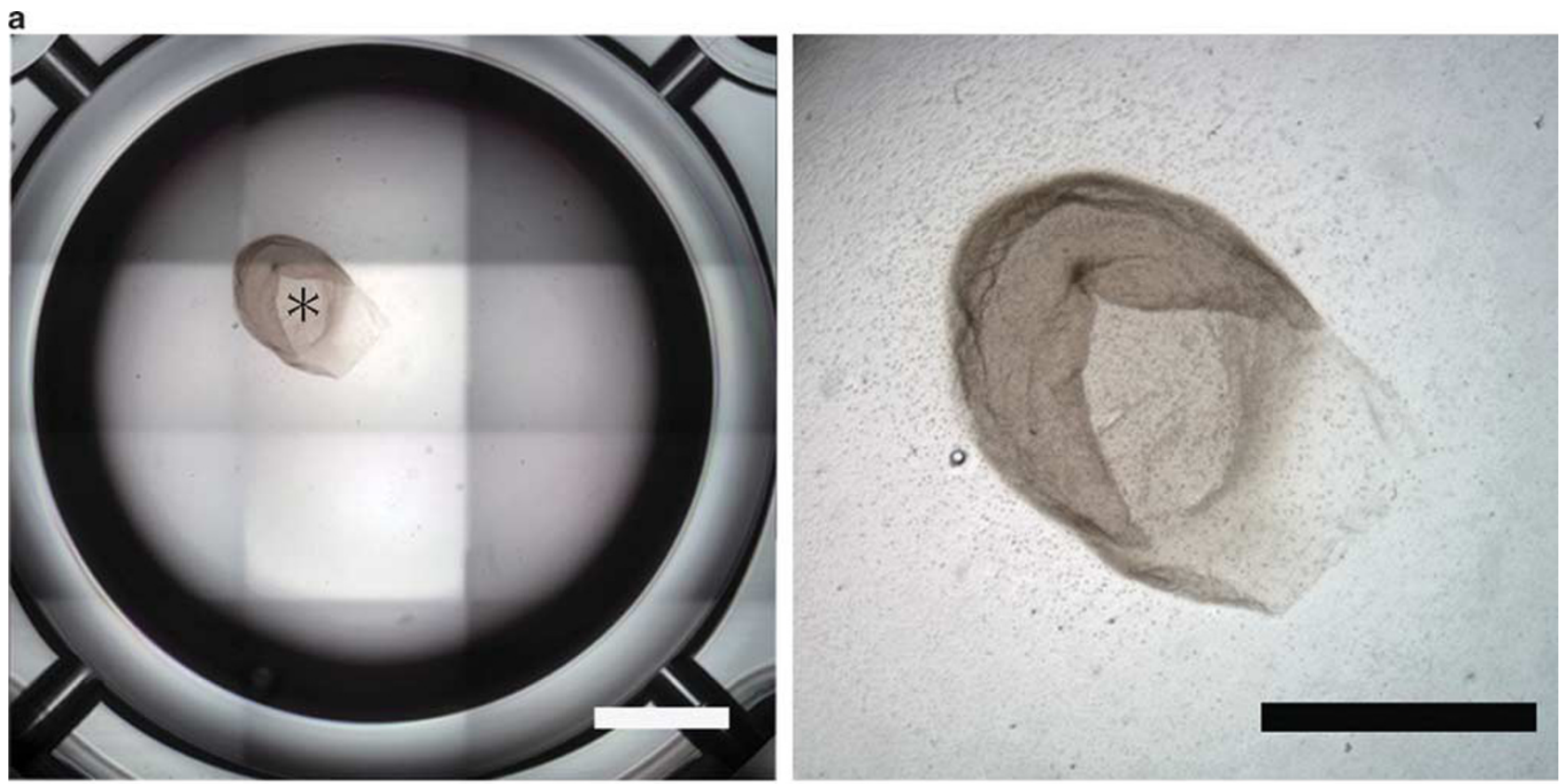

b
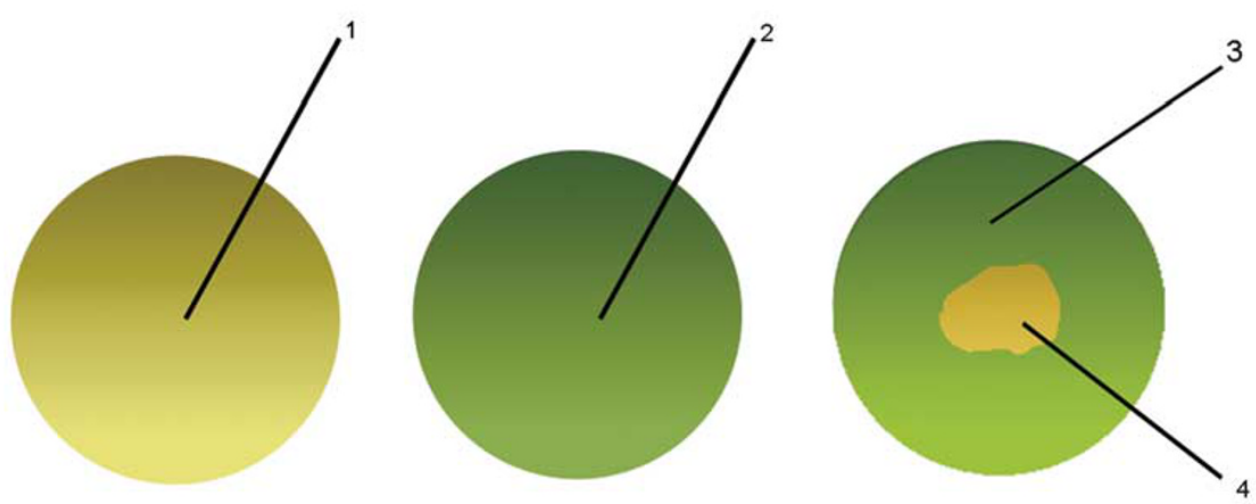

C

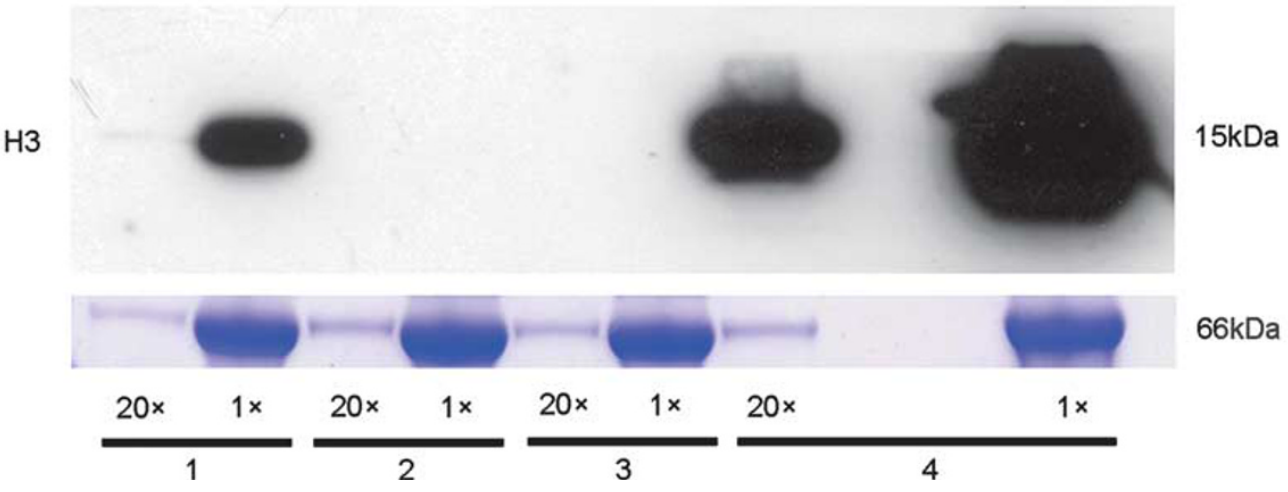

Figure 7 Results of mixing vitreous and histones. (a) Biomicroscopic photograph of vitreous with histones. An aggregated cluster was observed in the middle of the culture dish (asterisk). (b) Schematic drawing of the sample collection area for western blot analysis. The media contained $50 \mu \mathrm{g} / \mathrm{ml}$ histones ( 1 , yellow circle), vitreous body without histones ( 2 , green circle), and vitreous body with histones ( 3 and 4 , green circle and yellow oval). Sample 3 was collected from the vitreous in which aggregation clusters were not observed, and sample 4 was collected from an aggregated cluster in the middle of the vitreous body. (c) Western blot showing that histone H3 was present in the medium containing histones (lane 1) but was not found in vitreous alone (lane 2) or vitreous body that was distant from an aggregated cluster (lane 3). Histone $\mathrm{H} 3$ was concentrated in aggregated clusters (lane 4). Coomassie brilliant blue staining of the samples showed that the protein amounts were equal based on the $66 \mathrm{KDa}$ band. $20 \times$, diluted 20 times. Scale bars: $3000 \mu \mathrm{m}$. 
a

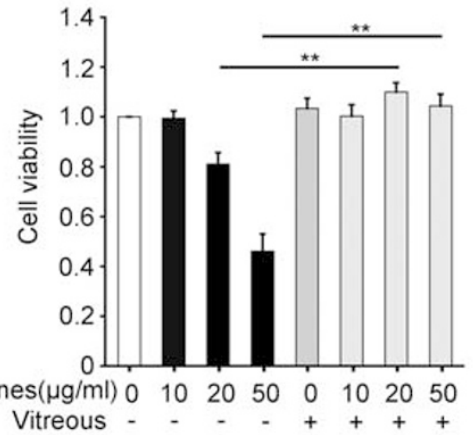

b

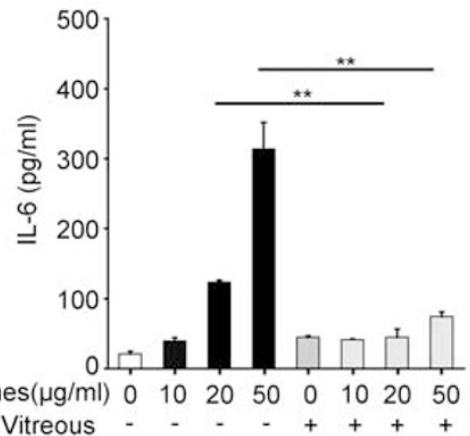

c

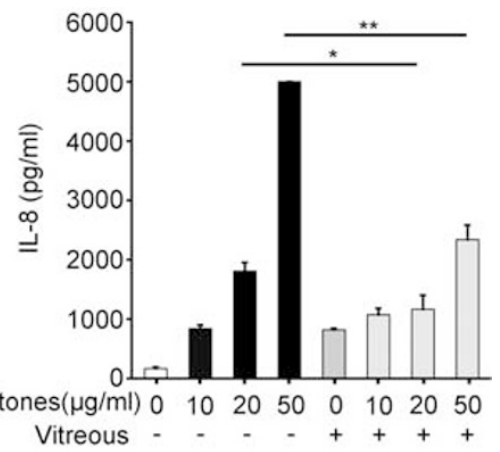

d

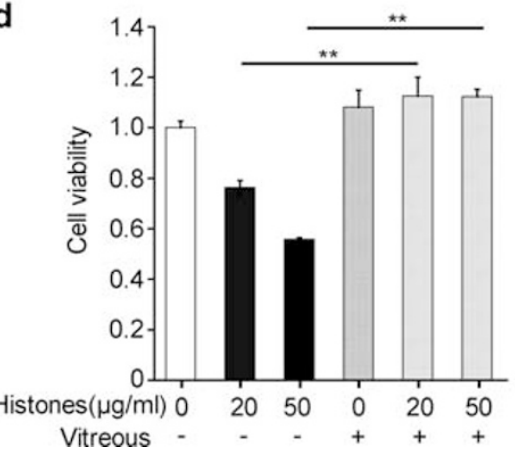

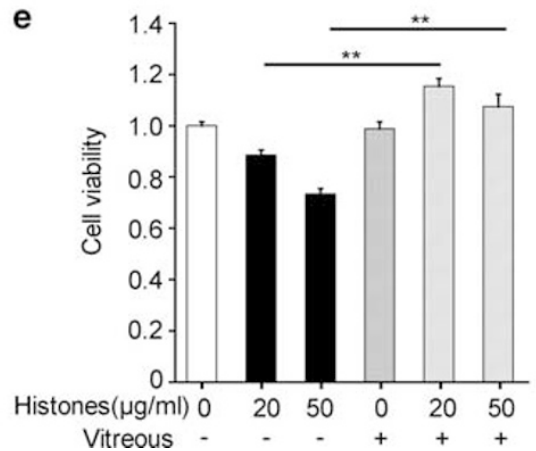

Figure 8 Effects of the vitreous on histone-induced cell viability and cytokine productions. ARPE-19 cells, porcine primary RPE cells, and R28 cells were treated with or without vitreous followed by incubation with histones for $18 \mathrm{~h}$. (a) Cell viability was increased in the presence of vitreous in ARPE-19 cells. (b, c) The production of IL-6 and IL-8 was significantly decreased in the presence of vitreous in ARPE-19 cells. (d) Cell viability was also increased in the presence of vitreous in porcine primary RPE cells. (e) Cell viability was also increased in the presence of vitreous in R28 cells. The experiments were performed in triplicate. The data are presented as mean \pm s.e.m., $n=4$. Student's $t$-tests: ${ }^{*} P<0.05,{ }^{* *} P<0.01$.

clusters with histones, and by doing so it prevented the spread of histones.

\section{DISCUSSION}

Our results showed that the concentration of histones was elevated in the vitreous of eyes with RD. We also found that histones were released from damaged retinal cells in vitro and were observed in the subretinal space of rats with a detached retina. The extracellular histones induced the production of IL- 6 and IL- 8 by the RPE cells and were associated with the apoptosis and necrosis of retinal and RPE cells in vitro. Furthermore, blocking the histones by antibodies reduced the retinal damage in eyes with $\mathrm{RD}$, and the toxic effects of the histones were blocked by their exposure to vitreous. To the best of our knowledge, this is the first study to demonstrate the presence of extracellular histones in human eyes with $\mathrm{RD}$ and to explore their possible pathological roles. More importantly, the intrinsic defense mechanisms against the toxic effects of histones in eyes were also studied.

Huang et $a l^{5}$ showed that the cytoplasm of hepatocytes was immunopositive for histones after hypoxia. In our in vitro study, histone $\mathrm{H} 3$ was found to move from the nucleus to the cytosol, and it was released from R28 cells upon exposure to oxidative stress induced by hydrogen peroxide. The extracellular histones then induced the secretion of the proinflammatory cytokines IL- 6 and IL- 8 through the ERK1/ 2 and p38 MAPK pathways but not the JNK pathway in
ARPE-19 cells. TLR4 was involved in these pathways, and this supports the findings of Abrams et $a l^{31}$ who reported that TLR4 is partially responsible for the induction of cytokines by histones after lung injury. ${ }^{28}$

IL-6 and IL- 8 are abundantly present in the vitreous of eyes with RD. ${ }^{11,33}$ The levels of these cytokines were recently reported to be very high in the subretinal fluid of eyes with RD. ${ }^{34-36}$ IL-6 is a pluripotent cytokine typically intended to prevent additional damage to tissues of the central nervous system. However, this cytokine may also be toxic to neurons and other retinal cells during inflammation. ${ }^{37}$ IL- 8 is a pluripotent chemokine that induces chemotaxis and phagocytosis that aids in the scavenging of cellular debris and also induces inflammation. ${ }^{38}$ Goczalik et $a l^{39}$ showed that the expression of the IL- 8 receptor in the glial cells of retinas with PVR and in the PVR membranes suggests a role for IL-8 in the initiation of reactive gliosis. Therefore, it is possible that IL- 6 and IL- 8 can modulate the subretinal environment after RD. In RD, IL- 6 and IL- 8 in the subretinal space might be produced by RPE cells that are stimulated by histones released from the detached retina. Our findings provide confirmatory evidence that histones function in $\mathrm{RD}$ as 'alarmin' or 'DAMP' molecules, the endogenous molecules that signal tissue and cell damage.

In eyes with $\mathrm{RD}$, apoptotic and necrotic retinal cells are frequently observed that would indicate that there are permanent visual impairments. ${ }^{10,11,17}$ The biological 

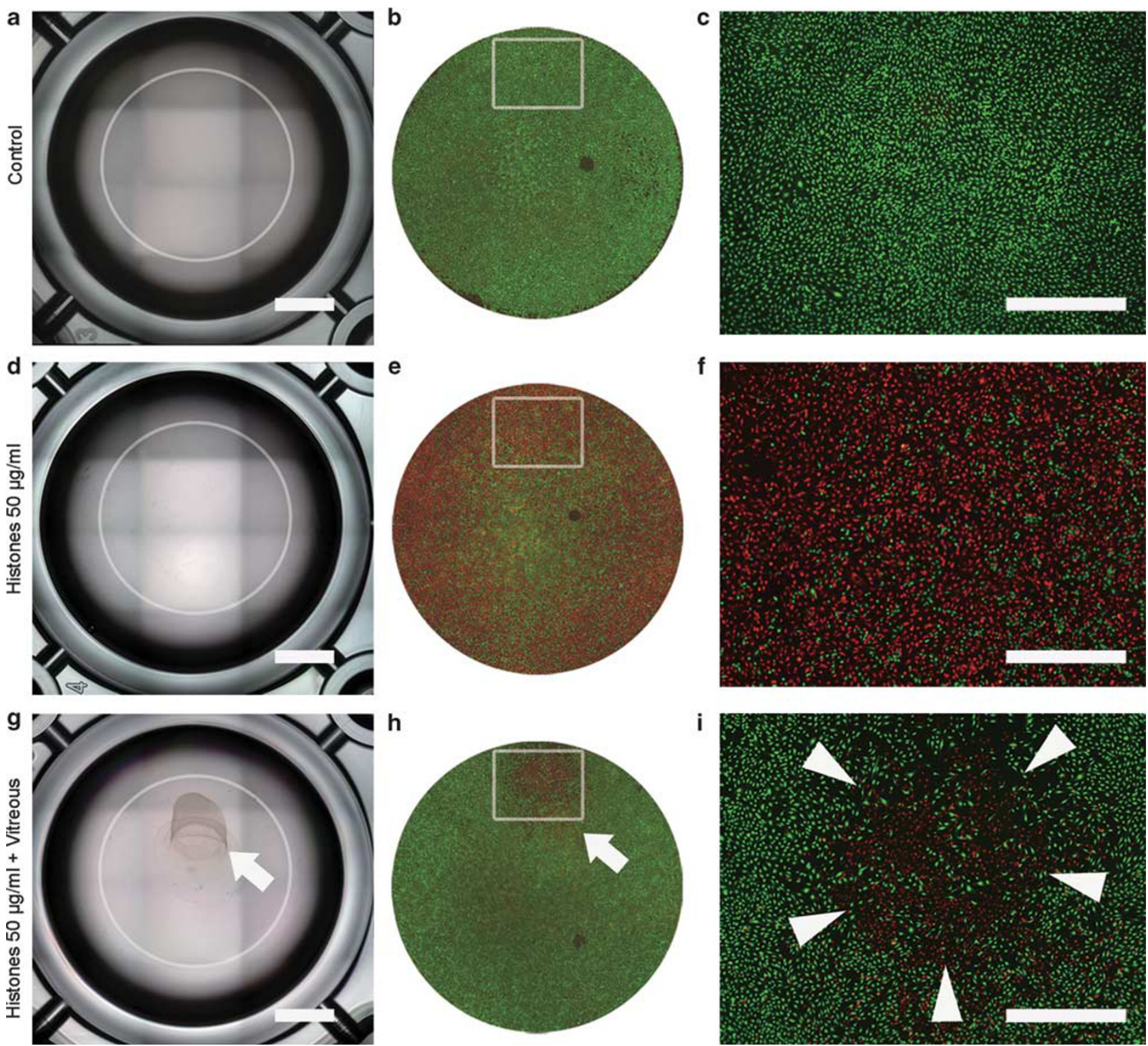

Figure 9 Vitreous body reduces the toxicity of histones to ARPE-19 cells. Viable cells stain green and damaged cells stain red after double staining with calcein-AM and PI in a 24-well plate. The cell viability was not affected by a medium containing vitreous (a-c). The cells were diffusely damaged by the medium containing histones $(50 \mu \mathrm{g} / \mathrm{ml})$, and the red-stained cells were diffusely distributed $(\mathbf{d}-\mathbf{f})$. (g) With vitreous and histones in the medium, an aggregated cluster can be observed in the middle of the vitreous (arrow). The damaged cells were limited within the area where histone clusters were present ( $\mathbf{h}$, arrow and $\mathbf{i}$, arrow head). ( $\mathbf{a}, \mathbf{d}$, and $\mathbf{g}$ ) are bright-field images of each well. ( $\mathbf{b}$, $\mathbf{e}$, and $\mathbf{h})$ are fluorescence images of the circles in $(\mathbf{a}, \mathbf{d}$, and $\mathbf{g}$ ) respectively. (c, $\mathbf{f}$, and $\mathbf{i})$ are magnified images of the squares in (b, e, and $\mathbf{h}$ ) respectively. Scale bars: (a, d, $\mathbf{g}) 3000 \mu \mathrm{m} ;(\mathbf{c}, \mathbf{f}, \mathbf{i}): 1000 \mu \mathrm{m}$.

spectrum of cell deaths is diverse and varies from apoptosis to necroptosis and pyroptosis. The signaling pathways for each of these processes have been determined to some extent. ${ }^{40}$ Although a more detailed examination of cell damage induced by extracellular histones is needed, our findings showed that histones released from damaged retinal cells caused direct damage to cells, leading to apoptosis and necrosis of retina cells and necrosis of RPE cells as DAMP molecules. Similar toxic effects of histones have been reported following other tissue injuries. In kidney cells, histones released from damaged cells aggravate renal injury through TLR2 and TLR4. ${ }^{32}$ In an animal model of hepatic ischemia and reperfusion injury, the levels of circulating histones are significantly higher, and neutralizing the histones significantly protects the tissues against further damage. ${ }^{5,41}$ In addition, the histones released extracellularly in response to an inflammatory challenge contribute to endothelial dysfunction, organ failure, and death during sepsis. ${ }^{6}$ Thus, this process of extracellular release of histones from damaged tissues might be ubiquitous in the body.

The cytotoxicity of histones and their enhancement of IL- 6 and IL-8 productions was blocked in the presence of vitreous. 
a

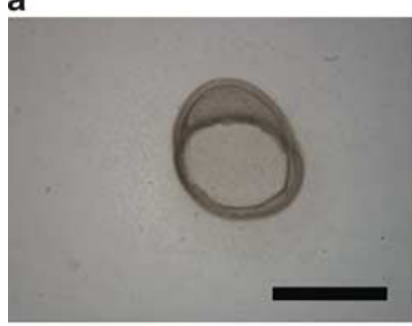

C
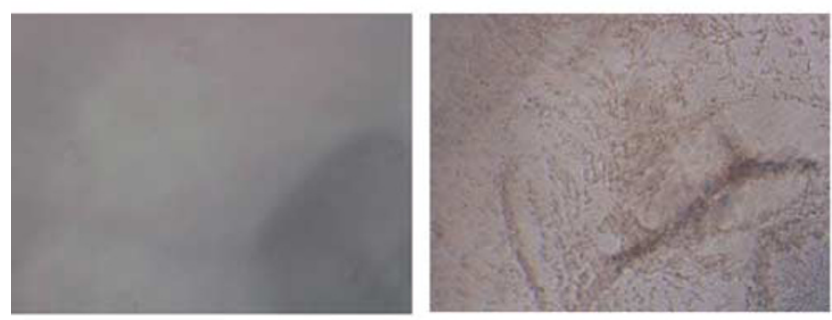

e

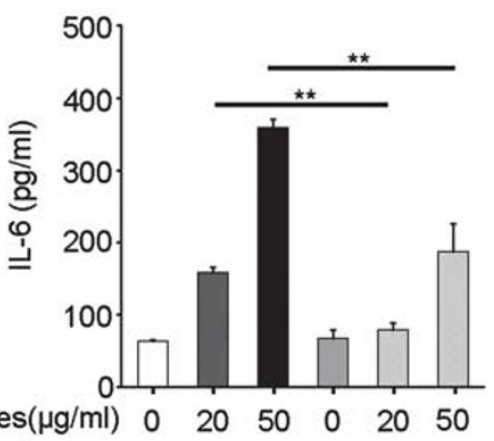

Hyaluronan - - +++

g

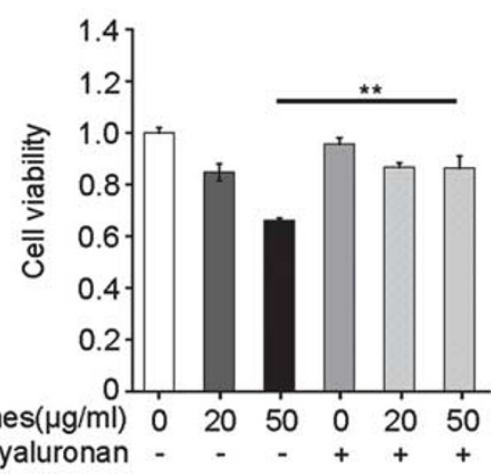

b
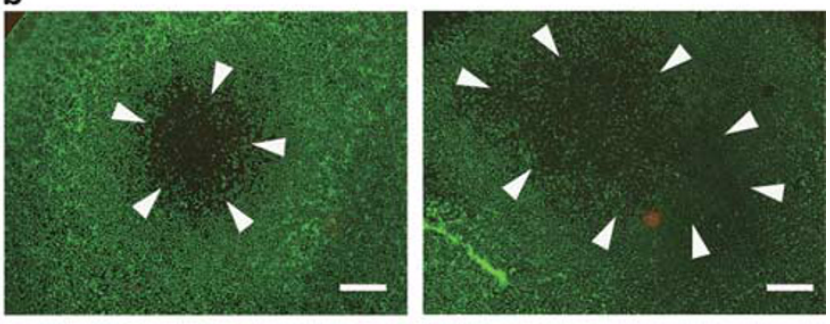

d

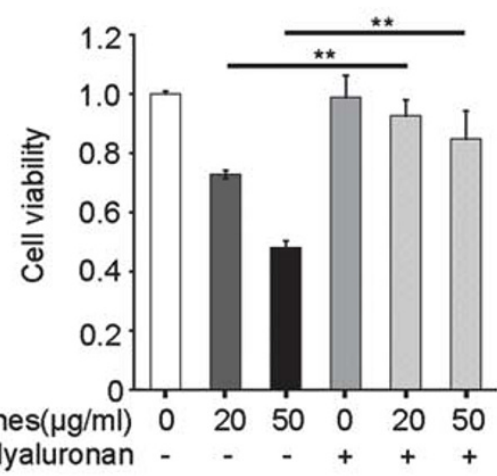

f

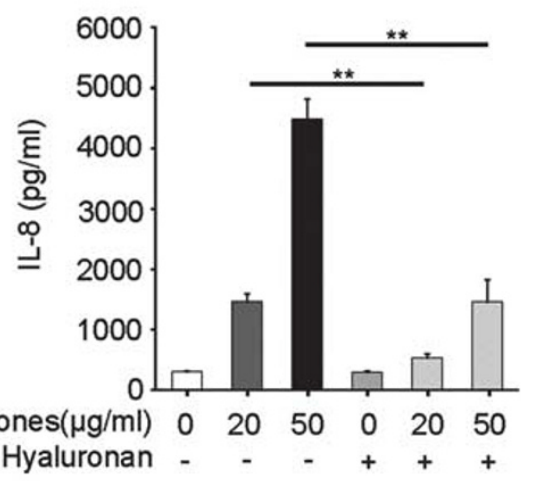

h

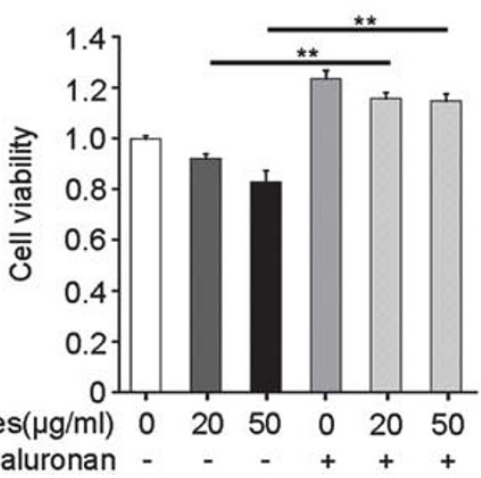

Figure 10 Role of hyaluronan in the vitreous body. (a) A cluster was formed immediately after the addition of a mixture of histones and vitreous (left). After pretreatment of the vitreous with hyaluronidase, a cluster was not formed (right). (b) Calcein-AM and PI staining show that Pl-positive areas (arrowheads) were enlarged after hyaluronidase treatment (left, no hyaluronidase; right, hyaluronidase) in ARPE-19 cells. (c) A cluster was not formed with a mixture of medium and histones (left). However, a cluster was formed with medium, hyaluronan, and histones (right) (original magnification, $\times 80$ ). (d) ARPE-19 cells were treated with or without hyaluronan before incubation with histones for $18 \mathrm{~h}$. Cell viability was significantly increased in the presence of hyaluronan as determined by a WST assay. (e, f) IL- 6 and IL-8 levels were assessed by CBA. The cytokine production was significantly reduced in the presence of hyaluronan in ARPE-19 cells. (g) Cell viability was also increased in the presence of hyaluronan in porcine primary RPE cells. (h) Cell viability was also increased in the presence of hyaluronan in R28 cells. The experiments were performed in triplicate. The data are presented as mean \pm s.e.m., $n=4$. Student's $t$-tests: ${ }^{* * P}<0.01$. Scale bars: $1000 \mu \mathrm{m}$. 
Because most histones are clumped together in the vitreous immediately after their release, this effect might be because of their trapping or localization by the vitreous. This process is biochemically reasonable because histones are strongly cationic and bind to glycosaminoglycans. ${ }^{42}$ Moreover, the trapping of histones by the vitreous was reduced by hyaluronidase, and the effect of hyaluronan on the histones was similar to that of the vitreous. Therefore, the inhibitory effect of the vitreous on the toxic effects of histones was likely caused by the hyaluronan present in the vitreous. Because phosphorylation of such proteins as ERK1/2, p38, or JNK was induced by histones, but not coincubation with hyaluronan or hyaluronan alone, this effect is likely because of the physical separation of histones and cells, and not by the alteration of signal transduction by hyaluronan.

Histone $\mathrm{H} 3$ was detected in the vitreous at significantly high concentrations in eyes with $\mathrm{RD}$. In an experimental $\mathrm{RD}$ model in rats, histone $\mathrm{H} 3$ was found in the subretinal space. Considering the direct connection between subretinal and vitreous spaces through the retinal hole, the intravitreal histones most likely originated from the detached retina. In our previous study, intravitreal HMGB-1 was significantly high in eyes with $\mathrm{RD},{ }^{10}$ and the size of the detached retina was significantly correlated with the intravitreal concentration of IL-6. ${ }^{11}$ Although the intravitreal histone $\mathrm{H} 3$ level was not always high in eyes with $\mathrm{RD}$, it was significantly higher than that of the controls. The intravitreal concentration of histone H3 was not correlated with the level of intravitreal IL- 6 or IL8 or the size of the detached retina. In addition, the average intravitreal concentration of histone $\mathrm{H} 3$ was 300 to 1000 times less than what was effective in our in vitro studies. It is possible that histones were largely trapped by the vitreous, and the intravitreal concentration of histones might be underestimated compared with the actual amount of histones released from the damaged tissue or the subretinal concentration. In fact, the same level of histones was found in the plasma of baboons given a lethal dose of Escherichia coli. ${ }^{4}$ Moreover, anti-histone $\mathrm{H} 3$ neutralizing antibodies had a significant rescue effect in rat RD models. Thus, we believed that extracellular histones from damaged retinas have cytotoxicity effects on the retina regardless of the dissociation of concentrations between vitreous from $\mathrm{RD}$ patients and in vitro experiments.

Although the important roles played by the vitreous during the formation of the eye in the embryonic stage are well known, the importance of the vitreous has not been completely determined in adult eyes. Our results showed that the vitreous plays an important role in protecting the intraocular environment, especially after tissue injury. It was quite surprising that hyaluronan is one of the key molecules involved in this phenomenon and that the mechanism is so simple but highly efficient. Because hyaluronan is ubiquitously distributed in the human body, it is possible that hyaluronan plays a similar protective role against tissue injury in other parts of the body. For example, hyaluronan is often injected into joints for the treatment of arthritis to produce space; however, its role might go beyond this space-producing effect. Thus, hyaluronan might play a protective role against the cytotoxic and inflammatory effects of extracellular histones that can aggravate tissue damage. ${ }^{43}$

This study has some limitations. Gene silencing methods, such as siRNA, might be a better method for determining the role(s) of a specific molecule. However, our previous studies showed that pharmacologic agents sufficiently inhibited specific molecules, and thus pharmacological inhibitors were used in these experiments. ${ }^{20,21}$ It should be noted that a pharmacological approach is not always specific to a single molecule. Although the present RD model is an established rodent model, it is not a perfect model for clinical RD. In addition, the results obtained from cell lines in vitro do not always reflect those of cell in situ. For example, the cytotoxic effects of histones were found similarly in both ARPE-19 cells and porcine primary RPE cells in this study. However, significant secretion of IL-6/IL-8 was induced in ARPE-19 cells but not in porcine primary RPE cells (data not shown). We cannot explain this discrepancy because of species differences or primary cultures. These factors should be taken into account when interpreting and generalizing on the present findings.

In summary, a detached retina releases histones from damaged retinal cells that modulate the subretinal microenvironment after tissue injury as do the DAMP molecules. During this process, the vitreous may play an important role in protecting tissues from excessive damage. Considering the ubiquitous distribution of hyaluronan throughout the human body and the simple but highly effective role of the vitreous in ameliorating the toxic effects of histones, similar mechanisms might function as defensive network systems after tissue injury.

Supplementary Information accompanies the paper on the Laboratory Investigation website (http://www.laboratoryinvestigation.org)

\section{ACKNOWLEDGMENTS}

We thank all the staff members of the Institute of Laboratory Animal Sciences, Kagoshima University (Frontier Science Research Center), who kept the animals in good condition, and the Joint Research Laboratory, Kagoshima University Graduate School of Medical and Dental Sciences, for the use of their facilities. This work was supported in part by a Grant from the Research Committee on Chorioretinal Degeneration and Optic Atrophy, Ministry of Health, Labor, and Welfare (to T Sakamoto) and by a Grant-in-Aid for Scientific Research (no. 20390450) from the Ministry of Education, Science, and Culture of the Japanese Government.

\section{DISCLOSURE/CONFLICT OF INTEREST}

The authors declare no conflict of interest.

1. Brinkmann V, Reichard U, Goosmann C, et al. Neutrophil extracellular traps kill bacteria. Science 2004;303:1532-1535.

2. Kaplan MJ, Radic M. Neutrophil extracellular traps: double-edged swords of innate immunity. J Immunol 2012;189:2689-2695. 
3. Chaput C, Zychlinsky A. Sepsis: the dark side of histones. Nat Med 2009;15:1245-1246.

4. $\mathrm{Xu} \mathrm{J}$, Zhang $\mathrm{X}$, Pelayo $\mathrm{R}$, et al. Extracellular histones are major mediators of death in sepsis. Nat Med 2009;15:1318-1321.

5. Huang H, Evankovich J, Yan W, et al. Endogenous histones function as alarmins in sterile inflammatory liver injury through Toll-like receptor 9 in mice. Hepatology 2011;54:999-1008.

6. Xu J, Zhang $\mathrm{X}$, Monestier $\mathrm{M}$, et al. Extracellular histones are mediators of death through TLR2 and TLR4 in mouse fatal liver injury. J Immunol 2011;187:2626-2631.

7. Matzinger P. Tolerance, danger, and the extended family. Annu Rev Immunol 1994;12:991-1045.

8. Yang L, Bula D, Arroyo JG, et al. Preventing retinal detachmentassociated photoreceptor cell loss in Bax-deficient mice. Invest Ophthalmol Vis Sci 2004;45:648-654.

9. Cook B, Lewis GP, Fisher SK, et al. Apoptotic photoreceptor degeneration in experimental retinal detachment. Invest Ophthalmol Vis Sci 1995;36:990-996.

10. Arimura N, Ki-i Y, Hashiguchi T, et al. Intraocular expression and release of high-mobility group box 1 protein in retinal detachment. Lab Invest 2009;89:278-289.

11. Otsuka H, Arimura N, Sonoda S, et al. Stromal cell-derived factor-1 is essential for photoreceptor cell protection in retinal detachment. Am J Pathol 2010;177:2268-2277.

12. Kleinberg $\Pi$, Tzekov RT, Stein $L$, et al. Vitreous substitutes: a comprehensive review. Surv Ophthalmol 2011;56:300-323.

13. Sebag J. Imaging vitreous. Eye 2002;16:429-439.

14. Arimura N, Otsuka $\mathrm{H}$, Yamakiri $\mathrm{K}$, et al. Vitreous mediators after intravitreal bevacizumab or triamcinolone acetonide in eyes with proliferative diabetic retinopathy. Ophthalmology 2009;116:921-926.

15. Otsuka H, Kawano H, Sonoda S, et al. Particle-induced endophthalmitis: possible mechanisms of sterile endophthalmitis after intravitreal triamcinolone. Invest Ophthalmol Vis Sci 2013;54:1758-1766.

16. Uchino $\mathrm{E}$, Sonoda $\mathrm{S}$, Kinukawa $\mathrm{N}$, et al. Alteration pattern of tear cytokines during the course of a day: diurnal rhythm analyzed by multicytokine assay. Cytokine 2006;33:36-40.

17. Hisatomi T, Sakamoto T, Murata T, et al. Relocalization of apoptosisinducing factor in photoreceptor apoptosis induced by retinal detachment in vivo. Am J Pathol 2001;158:1271-1278.

18. Murakami $Y$, Ikeda $Y$, Yonemitsu $Y$, et al. Inhibition of nuclear translocation of apoptosis-inducing factor is an essential mechanism of the neuroprotective activity of pigment epithelium-derived factor in a rat model of retinal degeneration. Am J Pathol 2008;173:1326-1338.

19. Neekhra A, Luthra $S$, Chwa $M$, et al. Caspase- $8,-12$, and -3 activation by 7-ketocholesterol in retinal neurosensory cells. Invest Ophthalmol Vis Sci 2007;48:1362-1367.

20. Shirasawa M, Sonoda S, Terasaki $H$, et al. TNF-alpha disrupts morphologic and functional barrier properties of polarized retinal pigment epithelium. Exp Eye Res 2013;110:59-69.

21. Terasaki $H$, Kase $S$, Shirasawa $M$, et al. TNF-alpha decreases VEGF secretion in highly polarized RPE cells but increases it in non-polarized RPE cells related to crosstalk between JNK and NF-kappaB pathways. PLoS One 2013;8:e69994.

22. Larrayoz IM, Huang JD, Lee JW, et al. 7-ketocholesterol-induced inflammation: involvement of multiple kinase signaling pathways via NFkappaB but independently of reactive oxygen species formation. Invest Ophthalmol Vis Sci 2010;51:4942-4955.

23. Wang $Y$, Bian $Z M, Y u$ WZ, et al. Induction of interleukin-8 gene expression and protein secretion by C-reactive protein in ARPE-19 cells. Exp Eye Res 2010;91:135-142.
24. Yuan Z, Feng W, Hong J, et al. p38MAPK and ERK promote nitric oxide production in cultured human retinal pigmented epithelial cells induced by high concentration glucose. Nitric Oxide 2009; 20:9-15.

25. Spitzer MS, Mlynczak T, Schultheiss $M$, et al. Preservative-free triamcinolone acetonide injectable suspension versus 'traditional' triamcinolone preparations: impact of aggregate size on retinal biocompatibility. Retina 2011;31:2050-2057.

26. Harooni M, McMillan T, Refojo M. Efficacy and safety of enzymatic posterior vitreous detachment by intravitreal injection of hyaluronidase. Retina 1998;18:16-22.

27. Hikichi $T$, Kado $M$, Yoshida A. Intravitreal injection of hyaluronidase cannot induce posterior vitreous detachment in the rabbit. Retina 2000;20:195-198.

28. Hisatomi T, Sakamoto T, Sonoda KH, et al. Clearance of apoptotic photoreceptors: elimination of apoptotic debris into the subretinal space and macrophage-mediated phagocytosis via phosphatidylserine receptor and integrin alphavbeta3. Am J Pathol 2003;162: 1869-1879.

29. Thalhamer T, McGrath MA, Harnett MM. MAPKs and their relevance to arthritis and inflammation. Rheumatology 2008;47:409-414.

30. Guha M, Mackman N. LPS induction of gene expression in human monocytes. Cell Signal 2001;13:85-94.

31. Abrams ST, Zhang N, Manson J, et al. Circulating histones are mediators of trauma-associated lung injury. Am J Respir Crit Care Med 2013;187:160-169.

32. Allam $R$, Scherbaum $C R$, Darisipudi $M N$, et al. Histones from dying renal cells aggravate kidney injury via TLR2 and TLR4. J Am Soc Nephrol 2012;23:1375-1388.

33. Yoshimura T, Sonoda KH, Sugahara M, et al. Comprehensive analysis of inflammatory immune mediators in vitreoretinal diseases. PloS one 2009;4:e8158.

34. Ricker LJ, Kijlstra A, Kessels AG, et al. Interleukin and growth factor levels in subretinal fluid in rhegmatogenous retinal detachment: a case-control study. PLoS One 2011;6:e19141.

35. Symeonidis C, Androudi S, Tsaousis KT, et al. Comparison of interleukin IL-6 levels in the subretinal fluid and the vitreous during rhegmatogenous retinal detachment. Cytokine 2012;57:17-18.

36. Symeonidis C, Papakonstantinou E, Androudi S, et al. Interleukin-6 and matrix metalloproteinase expression in the subretinal fluid during proliferative vitreoretinopathy: correlation with extent, duration of RRD and PVR grade. Cytokine 2012;59:184-190.

37. Erta M, Quintana A, Hidalgo J. Interleukin-6, a major cytokine in the central nervous system. Int J Biol Sci 2012;8:1254-1266.

38. Ghasemi H, Ghazanfari T, Yaraee R, et al. Roles of IL-8 in ocular inflammations: a review. Ocul Immunol Inflamm 2011;19:401-412.

39. Goczalik I, Ulbricht E, Hollborn M, et al. Expression of CXCL8, CXCR1, and CXCR2 in neurons and glial cells of the human and rabbit retina. Invest Ophthalmol Vis Sci 2008;49:4578-4589.

40. Fink SL, Cookson BT. Apoptosis, pyroptosis, and necrosis: mechanistic description of dead and dying eukaryotic cells. Infect Immun 2005; 73:1907-1916.

41. Huang H, Chen HW, Evankovich J, et al. Histones activate the NLRP3 inflammasome in Kupffer cells during sterile inflammatory liver injury. J Immunol 2013;191:2665-2679.

42. Pemberton AD, Brown JK, Inglis NF. Proteomic identification of interactions between histones and plasma proteins: implications for cytoprotection. Proteomics 2010;10:1484-1493.

43. Sinusas K. Osteoarthritis: diagnosis and treatment. Am Fam Physician 2012;85:49-56. 